\title{
Microporosity in aluminium foams
}

\author{
M. Mukherjee ${ }^{1,2, *}$, F. García-Moreno², C. Jiménez ${ }^{2}$, A. Rack³ , J. Banhart ${ }^{2,4}$ \\ ${ }^{1}$ Department of Metallurgical and Materials Engineering, Indian Institute of Technology Madras, \\ Chennai 600036, India \\ ${ }^{2}$ Institute of Applied Materials, Helmholtz-Zentrum Berlin, Hahn-Meitner-Platz 1, 14109 Berlin, \\ Germany \\ ${ }^{3}$ European Synchrotron Radiation Facility, 38043 Grenoble Cedex, France \\ ${ }^{4}$ Institute of Materials Science and Technology, Technische Universität Berlin, \\ Hardenbergstrasse 36, 10623 Berlin, Germany
}

\begin{abstract}
We studied microporosity in the metallic matrix of aluminium foams produced by the powder metallurgical route both with and without application of a blowing agent. Microporosity was studied in-situ in liquid metal foams as well as ex-situ in the solidified microstructures. In-situ studies were carried out using synchrotron X-rays. Quantitative analyses of the amount and distribution of microporosity inside cell walls, Plateau borders and nodes were performed on 2D micrographs and on 3D reconstructed volumes generated by X-ray tomography. We studied the influence of alloying elements, blowing agent and holding time on the amount and type of micropores. The mechanisms of microporosity formation and the evolution of microporosity via diffusion of hydrogen and by coalescence are discussed. It was observed that alloy composition and holding time have a strong influence on microporosity. Different possible strategies to control microporosity are suggested.
\end{abstract}

Keywords: Metal foam; Solidification; Defects; Hydrogen diffusion; Microporosity 
*Corresponding author: manas.mukherjee@iitm.ac.in

\section{Introduction}

Microporosity is inevitable in aluminium alloys [1-4]. The amount of microporosity is determined by the solidification conditions and alloying elements. While insufficient feeding during solidification leads to shrinkage microporosity, the difference in hydrogen solubility between liquid and solid aluminium results in gas microporosity [2]. Microporosity adversely affects properties such as tensile [1, 4] and fatigue strength [3] because it promotes stress concentration. Foams made from aluminium alloys also contain such microporosity. We study it in this article.

At present, the disparity between the predicted and measured strength of aluminium foams is attributed to the presence of a non-uniform cell size distribution and defects such as missing or broken cell walls, elliptical cells and the curvature of cell walls [5-7]. However, the effect of microporosity is not taken into account. It has been reported that castings of thin sections are more vulnerable to the effects of micropores because they reduce the load-bearing cross section considerably [1]. The same also applies to closed-cell metal foams, which are made of thin sections such as cell walls and Plateau borders, usually with thicknesses of 50-300 $\mu \mathrm{m}$. This implies that the tensile and fatigue properties of closed-cell metal foams are also affected by microporosity.

According to the most simple model, the plastic collapse stress of foams scales with the relative density of foams as follows [8]:

$$
\frac{\sigma_{p l}^{*}}{\sigma_{y s}}=0.3 \times\left(\phi \frac{\rho^{*}}{\rho_{s}}\right)^{3 / 2}+0.4 \times(1-\phi) \frac{\rho^{*}}{\rho_{s}},
$$

the solid cell wall material. $\phi$ is the volume fraction of solid contained in the cell edges and the 
remaining fraction (1- $\phi)$ is in the cell faces. In Eq. (1), the first term is for the bending of cell edges (Plateau borders) and the second term is for the stretching of cell faces (cell walls). A similar relationship that includes bending and stretching components also exists for Young's modulus. While stretching immediately implies tensile stresses, bending involves both tensile and compressive stresses. Indeed, it is shown from in-situ compression tests of aluminium foams that even under compressive loading, tensile stress is generated [9]. Therefore, beside under tensile and fatigue loading, metal foams are expected to be susceptible to the effects of microporosity under compressive loading as well. While $\rho^{*}$ in Eq. (1) takes into account the total porosity of the foam it does not provide any clue about the amount of microporosity. For example, a foam with $\rho^{*}=0.18$ has $82 \%$ porosity and $18 \%$ solid fraction. Let us assume that out of this $82 \%$ porosity $2 \%$ is present in the form of microporosity in the microstructure of the solid part and the remaining $80 \%$ porosity is related to the volume of the cells. This implies that the microstructure of the cell walls, Plateau borders and nodes contains 10\%microporosity. While the influence of $2 \%$ porosity on the mechanical properties of a foam is marginal, the effect of $10 \%$ microporosity on the tensile strength of the metallic constituent cannot be ignored [10]. This implies that the relative density alone cannot predict the mechanical properties of a foam and the effect of microporosity should also be considered.

Ohgaki et al. [11] and Toda et al. [9, 12] were the first to draw attention towards the effect of microporosity in aluminium foams. A high level of microporosity (26\% of the metal volume) was reported [11]. It was shown that in metal foams subjected to compressive stress, cracks originate from micropores with diameters between $30 \mu \mathrm{m}$ and $350 \mu \mathrm{m}$. This is because large strains accumulate at such micropores and therefore the borders of them can be crack 
initiation sites [11]. Our own previous study has also shown that under compression of foams cracks are generated at micropores of deformed cell walls [13].

The goal of the present work is to quantify the amount and type of microporosity in aluminium alloy foams and clarify the mechanisms of microporosity formation. We also propose strategies to modify foams in section 4.6.

\section{Experimental}

\subsection{Materials}

Aluminium (Alpoco, 99.7\% pure, $\mathrm{D}_{50}=38 \mu \mathrm{m}$ ), silicon (Wacker Chemie, 99.5\% pure, $\mathrm{D}_{50}=$ $26 \mu \mathrm{m}$ ), copper (Chempur, 99.5\% pure, $\mathrm{D}_{50}=27 \mu \mathrm{m}$ ), pre-alloyed AlMg50 (Possehl Erzkontor GmbH, purity not specified) and $\mathrm{TiH}_{2}$ serving as blowing agent (Chemetall, Grade N, 98.8\% pure, $D_{50}=14 \mu \mathrm{m}$ ) powders were used to prepare foamable precursors following the powder metallurgical $(\mathrm{PM})$ route. $\mathrm{D}_{50}$ is the value of the particle diameter at $50 \%$ in the cumulative distribution. The $\mathrm{TiH}_{2}$ powder was heat-treated at $480{ }^{\circ} \mathrm{C}$ for $180 \mathrm{~min}$ in air. To prepare the precursors, $30 \mathrm{~g}$ of metal powder were mixed with or without addition of 0.5 wt.\% of $\mathrm{TiH}_{2}$ powder in a tumbling mixer for 15 min. The powder blend was subjected to uni-axial compaction in a cylindrical die at $400{ }^{\circ} \mathrm{C}$ for 5 min applying a pressure of $300 \mathrm{MPa}$. Four alloys were prepared with $\mathrm{TiH}_{2}$ and two alloys without $\mathrm{TiH}_{2}$ as specified in Table 1. Alloy AlSi6Cu4(values in wt.\%) was prepared both with and without $\mathrm{TiH}_{2}$. Unless otherwise indicated, the version containing $\mathrm{TiH}_{2}$ is meant. AlCu13Mg4 was prepared only without $\mathrm{TiH}_{2}$. Cylindrical tablets (36 mm diameter, $~ 11 \mathrm{~mm}$ thickness) were obtained by uni-axial compaction. $10 \times 10 \times 4 \mathrm{~mm}^{3}$ large samples were cut out from these tablets for foaming, ensuring that the compaction direction was along the 4-mm long side of the sample. 


\subsection{Foaming procedures}

Two different furnaces were used for foaming. All samples containing $\mathrm{TiH}_{2}$ were foamed inside a steel mould in air using a lamp furnace equipped with two or three halogen lamps of $150 \mathrm{~W}$ power [14], see also Ref. [15]. The temperature was measured at the bottom surface of the sample. $\mathrm{TiH}_{2}$-free samples were foamed by gas pressure manipulation in a gas-tight pressure furnace equipped with a ceramic heating. The temperature was measured at the bottom surface of the sample and calibrated to extract the temperature of the foam interior (given in Table 1), see Ref. [15].

$\mathrm{TiH}_{2}$-containing samples were foamed by heating them to above their melting point ata heating rate of 2-3 K/s. After the temperature had reached the foaming temperature it remained at or slightly above that level for a period which is denoted as holding time (HT). After holding, the foam was solidified by ambient cooling at an average cooling rate of initially about $1 \mathrm{~K} / \mathrm{s}$. To foam $\mathrm{TiH}_{2}$-free samples, the powder compacts were first heated up to the foaming temperature inside the pressure furnace filled with argon at 5 bar pressure. After melting the samples, the gas pressure was released to ambient pressure (1 bar) within 30 s. The pressure drop immediately induced expansion of the sample by the release and expansion of adsorbed gases present in the powder compact. This process is referred to as pressure induced foaming (PIF) [16-17]. After pressure release, the experimental course was identical to that of the samples containing blowing agent.

\subsection{In-situ observation of foaming}

Foaming of $\mathrm{Al}$ and $\mathrm{AlSi6Cu} 4$ was observed in-situ by radioscopy using hard X-ray synchrotron radiation at beamline ID19 of the European Synchrotron Radiation Facility. A mixed mode of 
absorption and phase contrast was used for image acquisition that ensures high visibility of the cell walls. In the phase contrast mode, the contrast of the liquid-gas interfaces is dominated by refraction effects. The details of the experimental technique are given in [18-19]. Briefly, the white radiation from the beamline's wiggler insertion device (gap $40 \mathrm{~mm}$ ) was used for illumination (energy 34 keV). As detector a 300- $\mu$ mthick YAG:Ce scintillator was coupled by a 1× magnifying lens to a high-speed CMOS camera (pco.1200hs, PCO AG, Germany) located several meters downstream of the sample.

\section{4. ctural characterization}

The solidified foams were sectioned into two halves. One half was used for optical microscopy. The samples were embedded in cold-curing resin (Kulzer), mechanically ground using 120-4000 grit silicon carbide paper, polished successively with $3 \mu \mathrm{m}$ and $1 \mu \mathrm{m}$ diamond paste, and finally polished with a $\mathrm{SiO}_{2}$ suspension on a smooth cloth. ImageTool version 3.00 software was used to analyse the microporosity from the micrographs.

From the other half of the AlSi6Cu4, AlSi6Cu4 without $\mathrm{TiH}_{2}$ and AlCu13Mg4 alloy foams a small piece approximately $5 \times 5 \times 8 \mathrm{~mm}^{3}$ in size was excised for X-ray tomography. A micro-focus X-ray source and a flat panel detector (both supplied by Hamamatsu, Japan) were used. The X-ray source was operated at $100 \mathrm{kV}$ voltage,100 $\mu \mathrm{A}$ current and $5 \mu \mathrm{m}$ spot size. The sample was rotated through $360^{\circ}$ in 1000 steps while acquiring images after each step. 3D reconstruction of the data was performed using the commercial software Octopus (Inside Matters, Gent, Belgium). After reconstruction, the commercial software VGStudioMax 1.2.1 (Volume Graphics, Heidelberg, Germany) was used to extract 2D and 3D sections of the foam.

In the present study, the source-sample-detector configuration resulted in a spatial resolution of 
7.5 $\mu \mathrm{m}$. The software MAVI 1.3.1 (Fraunhofer ITWM, Kaiserslautern, Germany) was used for volume image analysis of the tomographic data sets.

\section{Results}

\subsection{Microstructure}

Before introducing the results it is necessary to define the terms micropores and microporosity. Being a porous material, aluminium foam contains a wide range of pore sizes and there is no sharp boundary between small and large pores. Following the observation of Ohgaki et al. [11], we label pores as micropores that have an equivalent diameter $\leq 350 \mu \mathrm{m}$. This limit is similar to the average size of the micropores $(\approx 350 \mu \mathrm{m})$ observed in our own study [20]. In this article, the quantitative analysis presented (in Figs. 5and10) is based on pores with an equivalent diameter $\leq 350 \mu \mathrm{m}$. The total amount of microporesis referred to as microporosity. It is measured from the 2D micrographs of foam microstructures and defined as:

$$
\text { microporosity }=\frac{\text { total area of micropores }}{\text { area of the solid matrix including micropores }} .
$$

Accordingly, a certain level $\mathrm{X}$ of microporosity means that a fraction $\mathrm{X}$ of the area of the cell walls, Plateau borders and nodes is covered by micropores.

Figs. 1-4 show the microstructure (also macrostructure in Fig. 3c,d) of all the foams. The microstructures reveal two types of microporosity - gas and shrinkage porosity. The former comes as circular void embedded in the cell wall material. The latter appears non-circular and as voids situated between former solid phase particles.

The microporosity of each sample was measured by analysing five to ten micrographs obtained from different parts of each sample. The result for all the alloys is displayed in Fig. 5. The microporosity in pure $\mathrm{Al}$ and AlSi11 foams is less than that in AlSi7 foams, which contains 
14\% microporosity. Pure Al foams show only little, and AlSi7 and AlSi11 foams show no shrinkage microporosity, see Figs. 1a-1c, whereas the microstructure of AlSi7 foam reveals a significant amount of gas microporosity.

Fig. 2 shows how the microporosity in AlSi6Cu4 foam decreases with increasing HT (a to d). An enlarged view of a large and elongated micropore is shown in the inset of Fig. 2a. Here, the micropore reveals the contour of dendrites, which is a signature of shrinkage porosity. Its large size implies that it also must contain some gas microporosity. Since shrinkage micropores grow in interdendritic channels, they appear as a network of irregular pores in the adjacent dendritic arms as marked in Fig. 2b. For 200 s HT, the 2D microporosity in the AlSi6Cu4 foam matrix is about 9\%, which reduces to about 3\% for $1500 \mathrm{~s}$ or longer HT as shown in Fig. 5. An identical trend was observed forAlSi6Cu4 foams without $\mathrm{TiH}_{2}$. Microporosity decreases with HT as shown in Figs. 3a and 3b from about 9\% for 200 s HT to about 3\% for 1500 s HT. Unless otherwise specified, all the results and discussions for these two alloys correspond to $200 \mathrm{~s}$ HT. The macrostructures of the AlSi6Cu4 foams without $\mathrm{TiH}_{2}$ in Figs. $3 \mathrm{c}$ and $3 \mathrm{~d}$ reveal that while for 200 s HT there are many broken cell walls, the sample for 1500 s HT has only few of them. The AlCu13Mg4 foam matrix shows a large amount of microporosity, about $13 \%$, which is mostly gas porosity as evidenced by their circular shape in Fig. 4. No shrinkage microporosity was observed in this foam.

\subsection{In-situ studies}

Fig. 6 shows X-ray radioscopic images of AlSi6Cu4 foam in the liquid state. When a foam is liquid, a cell should be referred as bubble and a cell wall as film. Accordingly, a micropore in a liquid foam is referred to as microbubble. Plateau borders and nodes containing a large amount of melt are thicker than films. Microbubbles inside Plateau borders and nodes are of various 
sizes. Films contain only small microbubbles. It was observed that microbubbles coalesce with each other (see supplementary material A) as well as with bubbles of the foam as demonstrated in Fig. 6b and 6c.

Fig. 7a shows an X-ray radioscopic image of an $\mathrm{Al}$ foam in the liquid state in which several microbubbles can be seen. Six of them are marked by numbers. It was observed that microbubbles shrink with time. This was quantified by measuring the radius (assuming perfect sphericity) of these six microbubbles at $10 \mathrm{~s}$ interval for $40 \mathrm{~s}$. The evolution of radius with time is given in Fig. 7cand shows that all microbubbles shrink with time but at a different rate. The zero value of radius for microbubble no.5 after $30 \mathrm{~s}$ indicates that this microbubble has disappeared after $30 \mathrm{~s}$. The radiographs of all stages are provided in supplementary material B.

\section{3. $3 D$ distribution of pores}

3D arrangements of micropores in $\mathrm{AlSi} 6 \mathrm{Cu} 4$, AlSi6Cu4 without $\mathrm{TiH}_{2}$ and $\mathrm{AlCu} 13 \mathrm{Mg} 4$ foams are shown in Fig. 8. The micropores in the latter two foams are mostly spherical, whereas in AlSi6Cu4 they are both spherical and elongated. Cell walls are seen as the thinner regions between two cells, while the thicker regions are either Plateau borders or nodes.

Fig.9 reveals the 3D distribution of micropores embedded in the metallic matrix of AlSi6Cu4 foam. The micropores present in the nodes are the largest, while the ones in the cell walls are the smallest. The micropores in the Plateau borders are of intermediate size.

Fig. 10 compares the shape factor of the micropores in AlSi6Cu4, AlSi6Cu4 without $\mathrm{TiH}_{2}$ and AlCu13Mg4 foams. For a micropore of volume $V$ and surface area $S$ the shape factor is defined as:

$$
\text { Shape factor }=6 \sqrt{\pi} \frac{V}{\sqrt{S^{3}}},
$$


and takes values between 0 (far away from spherical shape) and 1 (spherical). A strong difference in the shape factor of large micropores in these three alloys is noticeable. For example, if the micropores larger than $100 \mu \mathrm{m}$ are compared, most of them in AlSi6Cu4 without $\mathrm{TiH}_{2}$ and AlCu13Mg4 foams are near-spherical showing a peak around a shape factor of 0.9. On the contrary, in AlSi6Cu4foamthere are many large and elongated micropores.

\section{Discussion}

In aluminium and its alloys microporosity is also known as solidification porosity since micropores form during solidification. This indicates that micropores are present in solid metal or during solidification, and not in a fully liquid metal. In this study, however, any pore (or bubble) that is microscopic in nature (see section 3.1) is defined as micropore (or microbubble) irrespective of whether it is present in liquid or solid metal.

\subsection{Shrinkage and gas microporosity}

Irregular micropores are caused by solidification shrinkage, while hydrogen precipitation during solidification creates near-spherical micropores. However, any of the micropores can be caused by any or both of the mechanisms since the morphology of a micropore is merely an indication of the predominant mechanism [2, 21].

In short freezing range alloys such as pure metals and alloys of near-eutectic composition, feeding takes place freely until the last melt has solidified. As a result, solidification shrinkage in these alloys is manifested as bulk shrinkage and not as microporosity. For long freezing range alloys, feeding is inhibited as soon as the amount of solidified fraction becomes too high to allow for easy liquid flow. This leads to the formation of shrinkage porosity $[2,21]$. AlSi6Cu4 alloy is a long freezing range type (melting range $92 \mathrm{~K}$, see Table 2), which is 
the reason why shrinkage microporosity forms in AlSi6Cu4 foams, see Fig. 2. On the other hand, even though $\mathrm{Al}$ and AlSi11 have a similar amount of solidification shrinkage as AlSi6Cu4, they do not show any significant amount of shrinkage porosity because of their short freezing range type, see Fig. 1a and 1c.

Because feeding is influenced by the solid fraction during solidification, it is necessary to estimate its amount in order to predict the level of difficulty in feeding. The equilibrium liquid fraction during solidification of AlSi7, AlSi6Cu4 and AlCu13Mg4 was calculated by the Calphad approach using the Thermo-Calc software [22] and the COST507 Gibbs energy database [23]. The result is displayed in Fig. 11. In the case of AlCu13Mg4 alloy, coming from the liquid state and reaching the eutectic temperature $\left(503^{\circ} \mathrm{C}\right)$, there is at least $25 \mathrm{wt} . \%$ eutectic liquid and 75 wt.\% solid. This implies that feeding is not much restricted before the ternary reaction takes place. In contrast, for AlSi6Cu4 alloy the solid fraction is more than 95 wt.\% long before the eutectic reaction, see Fig. 11. Therefore, although AlCu13Mg4 is a long freezing range alloy (melting range $101 \mathrm{~K}$, see Table 2), feeding in this alloy takes place without much resistance. At the eutectic temperature $\left(577^{\circ} \mathrm{C}\right)$ of AlSi7 alloy there is approximately 50 wt.\% of eutectic liquid which facilitates feeding during the later stage of solidification. Hence, shrinkage microporosity does not form in AlSi7 and AlCu13Mg4 alloys.

Molten aluminium reacts with atmospheric moisture and produces hydrogen, a part of which dissolves in the melt. Decomposition of the blowing agent also provides hydrogen and is an additional source of hydrogen in $\mathrm{TiH}_{2}$-containing foams. The melt gets saturated with the hydrogen from these sources of hydrogen. Since the hydrogen solubility in solid aluminium is lower than that in liquid aluminium, the dissolved hydrogen is rejected from the solid phase during solidification at the solid-liquid interface. In the presence of nuclei such as oxide 
particles, already formed solid phase, etc., hydrogen microbubbles nucleate and grow and eventually get trapped as micropores in the solid phase [2, 21]. Rejected hydrogen also diffuses to already formed bubbles in the foam. Microporosity formed from this gas consists of isolated micropores usually near-spherical in shape because they first appear as microbubbles within the liquid.

Metal foams made of aluminium alloys mostly contain such shrinkage and gas microporosity. For a given solidification condition, the amount of microporosity depends on the alloy composition. Values for the solidification shrinkage and hydrogen solubility in the alloys used in this work are given in Table 2. The solubility values quoted in the literature refer to the volume at $300 \mathrm{~K}$. When precipitated hydrogen forms micropores, one has to consider the effective volume at the precipitation temperature [15]. Based on this logic, hydrogen solubility at $700{ }^{\circ} \mathrm{C}$ was calculated using Wagner’s interaction parameters [24-25] and are presented here as effective volume. Previously, we have estimated the amount of hydrogen precipitation at the liquidus temperature $\left(T_{\mathrm{L}}\right)$ of aluminium alloys [15]; this is also given in Table 2. Following the logic applied in Ref. [15] the hydrogen precipitation in AlCu13Mg4 alloy was estimated to about 3.8 vol.\%.

Table 2 shows that hydrogen precipitation is the highest in pure Al, namely 5 vol.\%. However, the amount of microporosity appearing mainly as gas microporosity in $\mathrm{Al}$ foam is less than $1 \%$. Precipitated hydrogen diffuses to the surrounding atmosphere or to the cells while the foam is still in liquid state. The foaming temperature for $\mathrm{Al}$ foam was $670{ }^{\circ} \mathrm{C}, 50 \mathrm{~K}$ higher than that for the other alloys, which promotes faster diffusion of hydrogen compared to other alloy foams. 
It has been reported by Toda et al. that hydrogen rejected during solidification can be trapped at sites such as dislocations, grain boundaries, etc., in the form of atomic hydrogen [26]. However, in the presence of nucleation sites most of this hydrogen forms micropores. Since the foams in the present study were produced from metal powders, oxide particles originating from the fragmentation of the oxide layers originally present on the surfaces of metal powder particles provide sufficient nucleation sites. Moreover, before solidification, foam already contains bubbles which can easily accept the rejected hydrogen. Therefore, it can be concluded that in metal foams, most hydrogen rejected during solidification will appear as micropores rather than being trapped as atomic hydrogen.

The values of solidification shrinkage presented in Table 2 were extracted from Refs. [2, 27-28]. The measured microporosity in AlSi6Cu4 is about 9\% (Fig. 5). According to the data in Table 2, the maximum possible microporosity due to the combined effect of solidification shrinkage and gas precipitation can be about $8.5 \%$, which is very close to the observed value. Solidification shrinkage does not produce microporosity in AlSi7, AlSi11 and AlCu13Mg4 alloys as discussed earlier. Therefore, microporosity in these alloys can only be created by hydrogen precipitation, which is about $3 \%, 2 \%$ and $4 \%$ (by volume), respectively, while the measured microporosity in these alloys is about $14 \%, 5 \%$ and $13 \%$, respectively. These disparities point towards additional sources of gas that can form microporosity. It is noteworthy that gas micropores were also observed in liquid foams held at constant temperature above the liquidus/melting temperature of the alloy/metal, see Figs. 6 and 7.

\subsection{Other sources of gas for the formation of microporosity}

Metal foams produced bythe PM route contain two additional gas sources. One is the hydrogen that is produced by the decomposition of $\mathrm{TiH}_{2}$. The second gas source is the gas generated by the 
decomposition of adsorbates that are present in metal powders either as hydroxides [16-17] or other compounds, see Ref. [29]. The microbubbles shown in Figs. 6 and 7 are produced by either

or both of these gas sources. AlSi6Cu4 foams produced without $\mathrm{TiH}_{2}$ contain a similar amount of microporosity as AlSi6Cu4 foams produced with $\mathrm{TiH}_{2}$. This suggests that adsorbates, which are common to both the foams, contribute a major part of this $9 \%$ microporosity in addition to shrinkage and gas microporosity.

\subsection{Evolution of microporosity in liquid foam}

The evolution of microbubbles in liquid foams follows the same patterns as that of large bubbles. Both are governed by coalescence and gas diffusion. The liquid film between two adjacent microbubbles (or bubbles) thins due to gravity and capillary drainage. At some point, mechanical perturbations rupture the film and lead to the coalescence of the two microbubbles (or bubbles) [30]. Either two smaller microbubbles coalesce forming a larger one (see supplementary material, Fig. S1) or a microbubble coalesces with a bubble as shown in Figs. 6b and 6c. While the former event usually does not change the amount of microporosity, the latter reduces it. Similarly, microporosity is reduced through diffusion only if the gas of a microbubble diffuses into a bubble or to its surrounding.

The pressure inside a spherical microbubble is the sum of the metallostatic pressure, the atmospheric pressure (1 bar) and $\Delta p$, where $\Delta p$ is the pressure exerted by surface tensional forces as derived from the Young-Laplace equation:

$$
\Delta p=2 \gamma / r .
$$

Here, $\gamma$ is the surface tension of the liquid and $r$ is the radius of the microbubble. Although the surface tension of aluminium varies with oxygen content, alloying elements and temperature [3132], we use $\gamma$ of pure liquid aluminium, which at $660^{\circ} \mathrm{C}$ is about $1 \mathrm{Nm}^{-1}$ [33]. Accordingly, $\Delta p$ 
for a spherical microbubble of radius $10 \mu \mathrm{m}$ is 2 bar, whereas $\Delta p$ for a spherical bubble of radius $1 \mathrm{~mm}$ is only 0.02 bar. The hydrogen concentration in each interface - from liquid Al to microbubble $(\mathrm{Al}-\mu \mathrm{B})$ or from liquid $\mathrm{Al}$ to a bubble $(\mathrm{Al}-\mathrm{B})$ - is in equilibrium with the respective pressure $\Delta p$. Sievert's law states that hydrogen solubility increases with the square root of pressure. Consequently, the solubility of hydrogen is higher at the $\mathrm{Al}-\mu \mathrm{B}$ interface than at the $\mathrm{Al}-$ B interface.

Now we consider the diffusion of hydrogen from a microbubble of radius $r$ to a bubble of radius $R$ separated by a distance $d$ as depicted in Fig.12. This sketch reflects the situation of a micropore as shown in Fig. 4. For simplicity, a few assumptions are made: the gas of a given microbubble diffuses only to the next bubble. Since the entire surface of a microbubble is not at a constant distance from the bubble, diffusion will be different from different parts of the microbubble. We consider that diffusion takes place only through the shaded region, which represents the shortest path for diffusion andin 3D covers $10 \%$ of the total surface area of the microbubble. The shaded region is assumed to have a constant thickness $d$. If we consider a constant and linear concentration gradient between $\mathrm{Al}-\mu \mathrm{B}$ and $\mathrm{Al}-\mathrm{B}$ interfaces, then, according to Fick's first law, the diffusion rate from the microbubble to the bubble is given by [34]:

$$
\frac{d V}{d t}=-D_{H \rightarrow A l} \times \frac{\Delta C}{d} \times A \times 0.1
$$

$V$ is the volume of the microbubble, $A$ its surface area, $D_{H \rightarrow A l}$ is the diffusion coefficient of hydrogen in liquid Al, namely $3.32 \times 10^{-7} \mathrm{~m}^{2} \mathrm{~s}^{-1}$ at $660^{\circ} \mathrm{C}$ [35]. The negative sign in Eq. 5 implies that the volume of microbubble decreases with time. The factor $0.1(10 \%)$ expresses the definition of the diffusion zone. The hydrogen concentration difference $\Delta C$ between the $\mathrm{Al}-\mu \mathrm{B}$ and the Al-B interfaces can be estimated by applying Sievert's law (for details see Appendix A): 
$\Delta C=\frac{S_{H}}{\sqrt{P_{\mathrm{atm}}}}\left(\sqrt{P_{\mathrm{atm}}+\frac{2 \gamma}{r}}-\sqrt{P_{\mathrm{atm}}+\frac{2 \gamma}{R}}\right)$.

The metallostatic pressure is negligible for such a small volume of foam in the current study and has therefore been ignored in the total pressure term. $S_{\mathrm{H}}$ is the solubility of hydrogen in liquid Al at atmospheric pressure $\left(P_{\mathrm{atm}}=10^{5} \mathrm{~Pa}\right)$ and the value of $S_{\mathrm{H}}$ at $660{ }^{\circ} \mathrm{C}$ is about $0.05 \mathrm{~m}^{3} / \mathrm{m}^{3} \mathrm{of} \mathrm{Al}$ [34]. If from time $t=0$ to time $t=t^{\prime}$, the radius of the microbubble changes from $r$ to $r^{\prime}$, and if $d<<r$ then according to Ref. [34] Eq. 5 can be expressed as:

$$
t^{\prime}=\frac{\left(r-r^{\prime}\right) \cdot r \cdot d}{r^{\prime} \cdot D_{H \rightarrow A l} \cdot \Delta C \cdot 0.1}
$$

Assuming realistic values $R=1 \mathrm{~mm}, r=100 \mu \mathrm{m}, d=10 \mu \mathrm{m}$, then for $50 \%$ and $90 \%$ reduction in radius, $t^{\prime}$ is about $7.3 \mathrm{~s}$ and $66 \mathrm{~s}$, respectively. If the radius of a microbubble decreases, the pressure inside it increases resulting in a higher value of $C_{\mathrm{Al}-\mu \mathrm{B}}$. If we assume that $d$ remains unchanged then the rate of gas diffusion increases further with decreasing $r$. This means that the shrinkage of the microbubble is accelerated with time, which was not considered in the model above. Nevertheless, it becomes evident that microbubbles in close contact with a bubble tend to disappear within a few seconds.

This can be verified by the results presented in Fig. 7c where all the microbubbles shrink to half of their size in $30 \mathrm{~s}$ to $40 \mathrm{~s}$ and microbubble no. 5 completely disappears after $30 \mathrm{~s}$. It is not reasonable to compare these results directly with the estimation of gas loss through diffusion due to the following reasons. (a) The distance between a microbubble and a bubble cannot be derived from the X-ray projected images. (b) It is not clear whether during shrinkage of a microbubble its distance from a bubble remains constant or changes. (c) In the particular example of Fig. 7a, all the microbubbles are located in the outer surface layer of the foam. Therefore, diffusion to the surrounding atmosphere can also take place and the rate of diffusion 
will be even faster due to the larger pressure difference resulting in a larger concentration gradient. (d) It is also possible that these microbubbles still receive gas produced from the $\mathrm{TiH}_{2}$, which counteracts gas losses. Because of these unknown parameters it is difficult to verify the diffusion equation. Nevertheless, the time scale observed in Fig. 7c is in the same order as predicted by Eq. 7 .

The thickness $d$ has to be small enough for the shaded region in Fig. 12 to feel the influence of the pressure inside the microbubble. If a microbubble is far away from a bubble it remains in equilibrium with the surrounding melt since the melt being under1 bar pressure cannot dissolve more hydrogen than the solubility limit at the corresponding temperature permits. Consequently, no concentration gradient is established between the microbubble and the bubble. As discussed earlier, films (cell walls in solid foam) are thinner than Plateau borders and nodes. Because of this, the average distance between a microbubble and a bubble is smaller inside films compared to that inside Plateau borders and nodes. Therefore, the microbubbles inside films shrink or disappear faster than the microbubbles inside Plateau borders and nodes. In Figs. 8 and 9 only small microbubbles are found inside cell walls, while Plateau borders contain larger ones.

The above model is valid for hydrogen microbubbles that form by the decomposition of $\mathrm{TiH}_{2}$. When microbubbles form from the gas produced by the decomposition of adsorbates during the foaming process the diffusion scenario is different. The gas adsorbed by the surfaces of the aluminium powders used for processing foamable solid precursors are contained in several types of aluminium hydroxides that decompose upon heating into oxides and water vapour. For example, $\mathrm{Al}(\mathrm{OH})_{3}$ decomposes as follows [36]:

$2 \mathrm{Al}(\mathrm{OH})_{3} \rightarrow \mathrm{Al}_{2} \mathrm{O}_{3}+3 \mathrm{H}_{2} \mathrm{O}$. 
The water vapour readily reacts with $\mathrm{Al}$

$2 \mathrm{Al}+3 \mathrm{H}_{2} \mathrm{O} \rightarrow \mathrm{Al}_{2} \mathrm{O}_{3}+\mathrm{H}_{2}$

Microbubbles created in this way are then covered by the oxide that forms through these reactions. Chethan et al. have shown that in solidified zinc foams made following the PM route the surface of micropores (they called them 'satellite pores') is fully covered by oxide layers [37]. The diffusivity of hydrogen in $\mathrm{Al}_{2} \mathrm{O}_{3}$ is $3.32 \times 10^{-8} \mathrm{~cm}^{2} \mathrm{~s}^{-1}$ at $660^{\circ} \mathrm{C}$, which is five orders of magnitude smaller than that in liquid aluminium, see Ref. [34]. For this, the gas loss from such microbubbles in liquid foam is controlled by the oxide layer, which significantly slows down the process and makes these microbubbles stable for a longer time [34]. Hence, the microbubbles observed for longer holding times in liquid foams have more likely been created by hydrogen released from adsorbates than from $\mathrm{TiH}_{2}$.

The number of coalescence and the amount of diffusion are both time dependent and therefore their effect increases with HT[30, 34]. Therefore, microporosity decreases with increasing HT, see Figs. 2 and 5. For AlSi6Cu4 foams, microporosity reduces to a constant level of 3\% for 1500 s or longer HT. Interestingly, AlSi6Cu4 without $\mathrm{TiH}_{2}$ foam also contains 3\% microporosity for $1500 \mathrm{~s} \mathrm{HT}$. This again implies that a major part of this microporosity is created by the gas produced by adsorbates.

The foaming parameters were identical for AlSi7 and AlSi6Cu4 foams, but due to their different melting ranges AlSi6Cu4 remained in the liquid state longer than AlSi7. This results in a lower amount of microporosity in AlSi6Cu4 than in AlSi7 for the same HT. AlSi11 foams were held at a temperature $30 \mathrm{~K}$ above their liquidus temperature, which is higher compared to the superheating for AlSi7 and AlSi6Cu4 foams. Hence, AlSi11 foams were also held in the liquid state for a longer time than AlSi7 and AlSi6Cu4 foams. This led to a lower level of 
microporosity in AlSi11. On the other hand, even though AlCu13Mg4 has the longest melting range it contains a high level of microporosity (13\%). Compared to the other alloys, this alloy contains additional gas sources because the AlMg50 intermetallic alloy powder that was used to introduce Mg into this alloy contains a significant amount of hydrogen [29, 38]. Hence, a high level of microporosity is found here.

\subsection{Influence of microporosity on feeding}

The solidification mechanism of the metallic component of aluminium foams is different from that in bulk aluminium alloys for two reasons: the small thickness of the metallic component and the presence of microbubbles prior to solidification. In bulk alloys, microbubbles form towards the end of solidification, whereas in aluminium foams they are already present when solidification starts as becomes obvious from Figs. 6 and 7 where microbubbles are present in fully liquid foams. A schematic of the microstructure during the initial stage of solidification in the presence of microbubbles is shown in Fig. 13. Beside the initial microbubbles present prior to solidification additional ones will form at some point during solidification. The depiction of dendrites alongside microbubbles was conceptualized by looking at micrographs, e.g., see Figs. 2-4 and by consulting the review paper published by Lee et al. [39]. Moreover, Campbell suggested that for thin sections, where there are only few grains across the wall section, feeding is more difficult compared to thick sections [2]. This is because grains are restrained by their contact with the wall. This also applies to metal foams since the thicknesses of films/cell walls or Plateau borders are about $50 \mu \mathrm{m}-200 \mu \mathrm{m}$ and $100 \mu \mathrm{m}-1000 \mu \mathrm{m}$, respectively. This situation is similar to what is depicted in Fig. 13.

The microbubble that are present from the beginning of solidification modify melt feeding in two ways. The presence of microbubbles increases the effective viscosity of the melt 
similar to solid particles. However, under shear stresses, for instance during feeding, the viscosity decreases more than that of a particle-containing melt because microbubbles are deformable whereas solid particles are not [40-41]. Secondly, microbubbles are trapped in between growing dendrites and make feeding more difficult [42]. In metal foams, feeding therefore stops at an early stage compared to when bulk alloys solidify. Consequently, the amount of shrinkage microporosity is higher in metal foams than in bulk alloys. A microbubble trapped in the junction of dendrites can result in a large irregular micropore by merging with shrinkage microporosity [42-43], similar to what is shown in the inset of Fig. 2a. With increasing $\mathrm{HT}$, as microbubbles shrink/disappear as shown in Fig. 7, the number of such irregular micropores in decreases.

\subsection{Influence of micropores on structure of solidified foam}

During solidification of aluminium foams, solidification expansion generates defects, mostly broken cell walls [44]. The same defects may also form under the influence of microporosity. In comparison to $\mathrm{TiH}_{2}$-containing foams (Fig. 2), in $\mathrm{TiH}_{2}$-free foams the thickness of cell walls is small as seen in Figs. 3a and 3b. For instance, the micropore shown in the inset of Fig. 3c is separated by cells 1 and 2 by $15-\mu m$ to $20-\mu$ m thick cell walls. During solidification of these very thin cell walls (or films) feeding is largely inhibited thus causing these very thin parts of the cell wall to rupture. If this rupture takes place towards the end of solidification it cannot lead to the coalescence of the two adjacent cells or bubbles (cell 1 and 2) and consequently the cell wall is only partially broken [44]. As a result, the cell wall that contained this micropore appears broken in the solidified structure as seen in Fig. 3c. On the other hand, as the number of micropores decreases with increasing HT, such defects are also diminished, see Fig. 3d. 
In $\mathrm{TiH}_{2}$-containing foams, cell walls are thicker (compare Figs. 2 and 3) and therefore the number and extent of such defects is small. Still, such defects were observed in some cases. For instance in Fig. 14, the part of the cell walls separating a micropore from the adjacent cells breaks, creating a connection between the two cells.

Based on above results it can be stated that micropores can influence the cellular structure of metal foams by creating interconnections among cells. Solórzano et al. have shown that apparently closed-cell metal foams such as Alporas and Alulight foams have actually a large amount of interconnected cells [45]. The partially broken cell walls caused by the presence of micropores could contribute towards such interconnections. Such interconnections/defects could be beneficial in terms of fluid transport or sound attenuation, but they might be detrimental in terms of mechanical properties as they are for bulk alloys.

Because of the absence of shrinkage microporosity in AlSi6Cu4 without $\mathrm{TiH}_{2}$ and AlCu13Mg4 foams, most of the micropores are near-spherical as seen in Figs. 8 and 10. In AlSi6Cu4 foams, shrinkage micropores enhance the formation of large irregular micropores by merging with gas micropores as mentioned earlier.

\subsection{Controlling microporosity}

The present study shows that microporosity can be reduced by increasing HT or by choosing the right alloy composition. Beside this, reducing or even avoiding the use of a blowing agent may also be considered in order to achieve a structure containing fewer defects. Our previous study demonstrated that an increase in cooling rate reduces the size of both shrinkage and gas micropores [13]. Powder compaction under vacuum atmosphere led to an improved structure of foams compared to the foams produced from powder compacts that are processed in air [46]. 


\section{Conclusions}

- Aluminium foams contain micropores that are caused either by the individual or by the combined effect of gas precipitation and shrinkage of the solid constituents. While in bulk alloys the source of micropore-forming gas is hydrogen that precipitates during solidification, aluminium foams contain additional sources, namely the hydrogen produced by the blowing agent $\mathrm{TiH}_{2}$ and the decomposition products of adsorbates introduced by the metal powder.

- Unlike in bulk alloys, microbubbles are present even before solidification starts in aluminium foams.

- The gas produced by the adsorbates accounts for a major part to the microporosity formed in the liquid state especially when the holding time (HT) is short.

- The amount of microporosity in $\mathrm{TiH}_{2}$-containing and $\mathrm{TiH}_{2}$-free foams is the same, its amount decreasing with increasing HT.

- While foams of the short freezing range alloys such as pure aluminium and AlSi11show low levels of microporosity, the level is much higher in the long freezing range alloy foams.

- Micropores found inside cell walls are smaller than those found inside Plateau borders and nodes.

- For shorter HT, when the level of microbubbles is high, feeding is restricted, which leads to the formation of large irregular micropores. Micropores promote generation of macrostructural defects such as broken cell walls and cell interconnections. 


\section{Acknowledgements}

The authors would like to thank H. Kropf for preparation of metallographic samples and A.

Hilger for helping with X-ray tomography measurements. The first author would like to thank

K.C. Hari Kumar for doing the liquid fraction calculation.

\section{Appendix}

\section{Calculation of concentration difference}

According to Sievert's law the solubility of hydrogen in liquid aluminium is proportional to the square root of the pressure. If $S_{\mathrm{H}}$ is the solubility of hydrogen in liquid aluminium at atmospheric

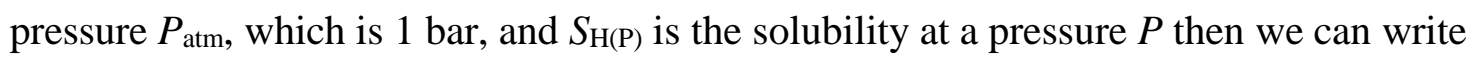

$$
\begin{aligned}
& \frac{S_{H}}{S_{H(P)}}=\sqrt{\frac{P_{\mathrm{atm}}}{P}} \\
& \text { or } S_{H(P)}=S_{H} \times \sqrt{\frac{P}{P_{\mathrm{atm}}}} .
\end{aligned}
$$

The pressure inside abubble $P_{\mathrm{B}}$ of radius $R$ is

$P_{B}=P_{\mathrm{atm}}+\frac{2 \gamma}{R}$

and the pressure inside a microbubble $P_{\mu B}$ of radius $r$ is

$P_{\mu B}=P_{\mathrm{atm}}+\frac{2 \gamma}{r}$.

Therefore, according to Eq. A2, the solubility of hydrogen at the Al-B interface is

$$
S_{A l-B}=\frac{S_{H}}{\sqrt{P_{\mathrm{atm}}}} \sqrt{P_{\mathrm{atm}}+\frac{2 \gamma}{R}}
$$

and the solubility of hydrogen at the $\mathrm{Al}-\mu \mathrm{B}$ interface is

$$
S_{A l-\mu B}=\frac{S_{H}}{\sqrt{P_{\mathrm{atm}}}} \sqrt{P_{\mathrm{atm}}+\frac{2 \gamma}{r}}
$$


Under equilibrium conditions, the concentration $C$ of hydrogen at the respective interface is equal to its solubility limit [34]. Therefore, the concentration difference $\Delta C$ between the two interfaces can be expressed as follows.

$\Delta C=C_{A l-\mu B}-C_{A l-B}=\frac{S_{H}}{\sqrt{P_{\text {atm }}}}\left(\sqrt{P_{\mathrm{atm}}+\frac{2 \gamma}{r}}-\sqrt{P_{\mathrm{atm}}+\frac{2 \gamma}{R}}\right)$ 
Table 1: Alloy compositions and foaming parameters. The initial cooling rate in all cases was

$1 \mathrm{~K} / \mathrm{s}$.

\begin{tabular}{lllll}
\hline $\begin{array}{l}\text { composition } \\
(\text { wt.\%) }\end{array}$ & $\begin{array}{l}\mathrm{TiH}_{2} \\
\text { used? }\end{array}$ & holding times (s) & $\begin{array}{l}\text { foaming (interior) } \\
\text { temperature }\left({ }^{\circ} \mathrm{C}\right)\end{array}$ & pressure profile \\
\hline Al & yes & 50 & 670 & $\begin{array}{l}\text { constant at } 1 \text { bar } \\
\text { constant at } 1 \text { bar }\end{array}$ \\
AlSi7 & yes & 200 & 620 & constant at 1 bar \\
AlSi11 & yes & 200 & 620 & constant at 1 bar \\
AlSi6Cu4 & yes & $200,600,1000,1500$, & 620 & \\
\hline AlSi6Cu4 & no & 200,1500 & 620 & 5 bar during melting, \\
& & & 620 & then reduced to 1 bar \\
& no bar during melting, & then reduced to 1 bar \\
\hline
\end{tabular}

Table 2: Solidification shrinkage, effective volume of hydrogen precipitation (prec.) and solubility (sol.) in $\mathrm{Al} / \mathrm{Al}$ alloys assuming hydrogen saturation in the melt. Volumes fractions are given at the liquidus temperature $T_{\mathrm{L}}$ and at $700{ }^{\circ} \mathrm{C}$.

\begin{tabular}{lclll}
\hline alloy & $\begin{array}{c}\text { melting } \\
\text { point/range, } \\
\left({ }^{\circ} \mathrm{C}\right)\end{array}$ & $\begin{array}{l}\text { solidification shrinkage } \\
(\text { vol.\%) / Ref. }\end{array}$ & $\begin{array}{l}\text { total } \mathrm{H}_{2} \text { prec. at } T_{\mathrm{L}} \\
(\text { vol.\%) } \\
{[15,47]}\end{array}$ & $\begin{array}{l}\mathrm{H}_{2} \text { sol. at } 700{ }^{\circ} \mathrm{C} \\
(\text { vol.\% }) \\
{[24-25]}\end{array}$ \\
\hline Al & 660 & $7 /[2]$ & & \\
AlSi7 & $577-617$ & $6 /[27]$ & 5 & 8 \\
AlSi11 & $577-590$ & $5 /[28]$ & 3.05 & 6.13 \\
AlSi6Cu4 & $519-611$ & $6 /[27]$ & 1.86 & 5.5 \\
AlCu13Mg4 & $503-604$ & Notknown & 2.5 & 4.9 \\
\hline
\end{tabular}

Melting range for AlSi7, AlSi6Cu4 and AlCu13Mg4 was extracted from the graphs in Fig. 11. The same for AlSi11 was extracted from [48]. 


\section{References}

[1] C.H. Cáceres, B.I. Selling, Casting defects and the tensile properties of an AlSiMg alloy, Mat. Sci. Eng. A 220 (1996) 109-116.

[2] J. Campbell, Castings: The New Metallurgy of Cast Metals, second ed., ButterworthHeinemann, Oxford, United Kingdom, 2003.

[3] M.J. Couper, A.E. Neeson, J.R. Griffiths, Casting defects and the fatigue behaviour of an aluminium casting alloys, Fatigue Frac. Eng. Mater.Struct. 13 (1990) 213-227.

[4] C.D. Lee, Effects of microporosity on tensile properties of A356 aluminum alloy, Mat. Sci. Eng., A 464 (2007) 249-254.

[5] E. Andrews, W. Sanders, L.J. Gibson, Compressive and tensile behaviour of aluminum foams, Mat. Sci. Eng., A 270 (1999) 113-124.

[6] I. Jeon, T. Asahina, The effect of structural defects on the compressive behavior of closed-cell Al foam, Acta Mater. 53 (2005) 3415-3423.

[7] Y. Sugimura, J. Meyer, M. He, H. Bart-Smith, J. Grenstedt, A. Evans, On the mechanical performance of closed cell Al alloy foams, Acta Mater. 45 (1997) 5245-5259.

[8] L. Gibson, M. Ashby, Cellular solids: structure and properties, Cambridge Univ Press, 1999.

[9] H. Toda, M. Takata, T. Ohgaki, M. Kobayashi, T. Kobayashi, K. Uesugi, K. Makii, Y. Aruga, 3-D image-based mechanical simulation of aluminium foams: effects of internal microstructure, Adv. Eng. Mater. 8 (2006) 459-467.

[10] A. Gokhale, G. Patel, Origins of variability in the fracture-related mechanical properties of a tilt-pour-permanent-mold cast Al-alloy, Scr.Mater. 52 (2005) 237-241. 
[11] T. Ohgaki, H. Toda, M. Kobayashi, K. Uesugi, M. Niinomi, T. Akahori, T. Kobayash, K. Makii, Y. Aruga, In situ observations of compressive behaviour of aluminium foams by local tomography using high-resolution X-rays, Phil. Mag. 86 (2006) 4417-4438.

[12] H. Toda, T. Kobayashi, M. Niinomi, T. Ohgaki, M. Kobayashi, N. Kuroda, T. Akahori, K. Uesugi, K. Makii, Y. Aruga, Quantitative assessment of microstructure and its effects on compression behavior of aluminum foams via high-resolution synchrotron X-ray tomography, Metall. Mater. Trans. A 37 (2006) 1211-1219.

[13] M. Mukherjee, U. Ramamurty, F. Garcia-Moreno, J. Banhart, The effect of cooling rate on the structure and properties of closed-cell aluminium foams, Acta Mater. 58 (2010) 50315042.

[14] F. Garcia-Moreno, N. Babcsan, J. Banhart, X-ray radioscopy of liquid metal foams: influence of heating profile, atmosphere and pressure, Coll. Surf. A 263 (2005) 290-294. [15] M. Mukherjee, F. Garcia-Moreno, J. Banhart, Solidification of metal foams, Acta Mater. 58 (2010) 6358-6370.

[16] F. Garcia-Moreno, J. Banhart, Foaming of blowing agent-free aluminium powder compacts, Coll. Surf. A 309 (2007) 264-269.

[17] F. García-Moreno, M. Mukherjee, C. Jiménez, J. Banhart, Pressure-induced foaming of metals, JOM 67 (2015) 955-965.

[18] F. Garcia-Moreno, A. Rack, L. Helfen, T. Baumbach, S. Zabler, N. Babcsán, J. Banhart, T. Martin, C. Ponchut, M. Di Michiel, Fast processes in liquid metal foams investigated by highspeed synchrotron x-ray microradioscopy, Appl.Phys. Lett. 92 (2008) 134104-134101-134103. 
[19] A. Rack, F. García-Moreno, L. Helfen, M. Mukherjee, C. Jiménez, T. Rack, P. Cloetens, J. Banhart, Hierarchical radioscopy using polychromatic and partially coherent hard synchrotron radiation, Appl.Opt. 52 (2013) 8122-8127.

[20] C. Jiménez, F. Garcia-Moreno, M. Mukherjee, O. Goerke, J. Banhart, Improvement of aluminium foaming by powder consolidation under vacuum, Scr. Mater. 61 (2009) 552-555.

[21] J. Anson, J. Gruzleski, The quantitative discrimination between shrinkage and gas microporosity in cast aluminum alloys using spatial data analysis, Mater. Charact. 43 (1999) 319-335.

[22] B. Sundman, B. Jansson, J.-O. Andersson, The thermo-calc databank system, Calphad 9 (1985) 153-190.

[23] I. Ansara, A. Dinsdale, M. Rand, COST 507 Definition of thermochemical and thermophysical properties to provide a database for the development of new light alloys: thermochemical database for light metal alloys, Office for Official Publications of the European Communities, 1998.

[24] P.N. Anyalebechi, Analysis of the effects of alloying elements on hydrogen solubility in liquid aluminum alloys, Scr. Metall. Mater. 33 (1995) 1209-1216.

[25] P.N. Anyalebechi, Attempt to predict hydrogen solubility limits in liquid multicomponent aluminum alloys, Scr. Mater. 34 (1996) 513-517.

[26] H. Toda, T. Hidaka, M. Kobayashi, K. Uesugi, A. Takeuchi, K. Horikawa. Growth behavior of hydrogen micropores in aluminum alloys during high-temperature exposure, Acta Mater. 57 (2009) 2277-2290.

[27] Thermotech Ltd, JMatPro: Materials property simulation package, United Kingdom. $<$ http://www.thermotech.co.uk/> 
[28] T. Magnusson, L. Arnberg, Density and solidification shrinkage of hypoeutectic aluminum-silicon alloys, Metall. Mater. Trans. A 32 (2001) 2605-2613.

[29] M. Mukherjee, F. Garcia-Moreno, C. Jiménez, J. Banhart, Al and Zn foams blown by an intrinsic gas source, Adv. Eng. Mater. 12 (2010) 472-477.

[30] F. Garcia-Moreno, E. Solorzano, J. Banhart, Kinetics of coalescence in liquid aluminium foams, Soft Matter 7 (2011) 9216-9223.

[31] C. Garcia-Cordovilla, E. Louis, A. Pamies, The surface tension of liquid pure aluminium and aluminium-magnesium alloy, J. Mater. Sci. 21 (1986) 2787-2792.

[32] J. Goicoechea, C. Garcia-Cordovilla, E. Louis, A. Pamies, Surface tension of binary and ternary aluminium alloys of the systems Al-Si-Mg and Al-Zn-Mg, J. Mater. Sci. 27 (1992) 52475252.

[33] B. Keene, Review of data for the surface tension of pure metals, Int. Mater. Rev. 38 (1993) 157-192.

[34] M. Mukherjee, F. Garcia-Moreno, J. Banhart, Collapse of aluminum foam in two different atmospheres, Metall.Mater. Trans. B 41 (2010) 500-504.

[35] W. Eichenauer, J. Markopoulos, Messung des Diffusionskoeffizienten von Wasserstoff in flüssigem Aluminium, Z. Metallkd.65 (1974) 649-652.

[36] K. Wefers, C. Misra, Oxides and hydroxides of aluminum, Alcoa Technical Paper No. 19, Alcoa Research Laboratories Center, Pittsburgh, PA, 1987.

[37] A. Chethan, F. Garcia-Moreno, N. Wanderka, B. Murty, J. Banhart, Influence of oxides on the stability of zinc foam, J. Mater. Sci. 46 (2011) 7806-7814.

[38] C. Jiménez, F. Garcia-Moreno, J. Banhart, G. Zehl, Effect of relative humidity on pressure-induced foaming (PIF) of aluminium-based precursors. in: L.P. Lefebvre, J. Banhart, D. 
Dunand (Eds.), Proceedings of Porous Metals and Metallic foams, Montreal, Canada.: DEStech Publications, 2007. pp.59-62.

[39] P.D. Lee, A. Chirazi, D. See, Modeling microporosity in aluminum-silicon alloys: a review, J. Light Met. 1 (2001) 15-30.

[40] M. Manga, M. Loewenberg, Viscosity of magmas containing highly deformable bubbles, J. Volcanol. Geotherm. Res. 105 (2001) 19-24.

[41] A.C. Rust, M. Manga, Effects of bubble deformation on the viscosity of dilute suspensions, J. Non-Newtonian Fluid Mech. 104 (2002) 53-63.

[42] D.M. Stefanescu, Science and engineering of casting solidification, second ed., Springer, New York, 2009.

[43] A.S. Sabau, S. Viswanathan, Microporosity prediction in aluminum alloy castings, Metall. Mater. Trans. B 33 (2002) 243-255.

[44] M. Mukherjee, F. Garcia-Moreno, J. Banhart, Defect generation during solidification of aluminium foams, Scr. Mater. 63 (2010) 235-238.

[45] E. Solórzano, M.A. Rodríguez-Pérez, J.A. de Saja, Do we really produce closed cell metallic foams?, in: J. Hirsch, B. Skrotzki, G. Gottstein (Eds.), Aluminum Alloys: Their Physical and Mechanical Properties, vol. Vol-2: Wiley-VCH, Weinheim, 2008. pp.2200-2206.

[46] C.E. Jiménez, Characterization and modification of powders used to make aluminiumbased metal foams. PhD Thesis, Technische Universität Berlin, 2009.

[47] P. Lutze, J. Ruge, Wasserstoff in Aluminium und seine Legierungen, Metall 8 (1990) 741-748.

[48] M. Mukherjee. Evolution of metal foams during solidification, PhD Thesis. Technische Universität Berlin, 2008. 
Figures
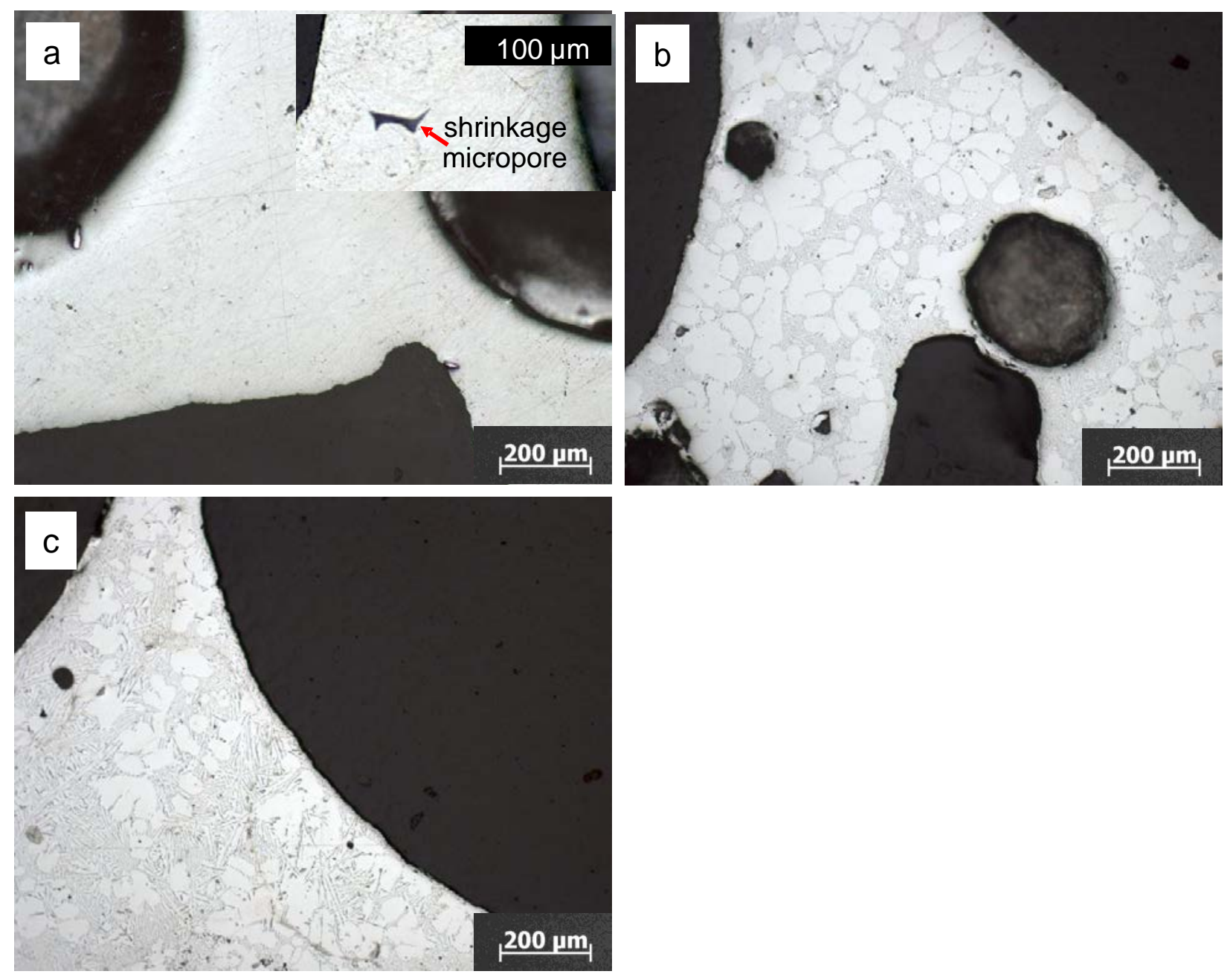

Figure 1: Microstructure of (a) pure Al, (b) AlSi7 and (c) AlSi11 foams. Inset in (a) shows shrinkage micropore in another region of the same sample. The HTs for (a), (b) and (c) are 50, 200 and 200 s, respectively. 

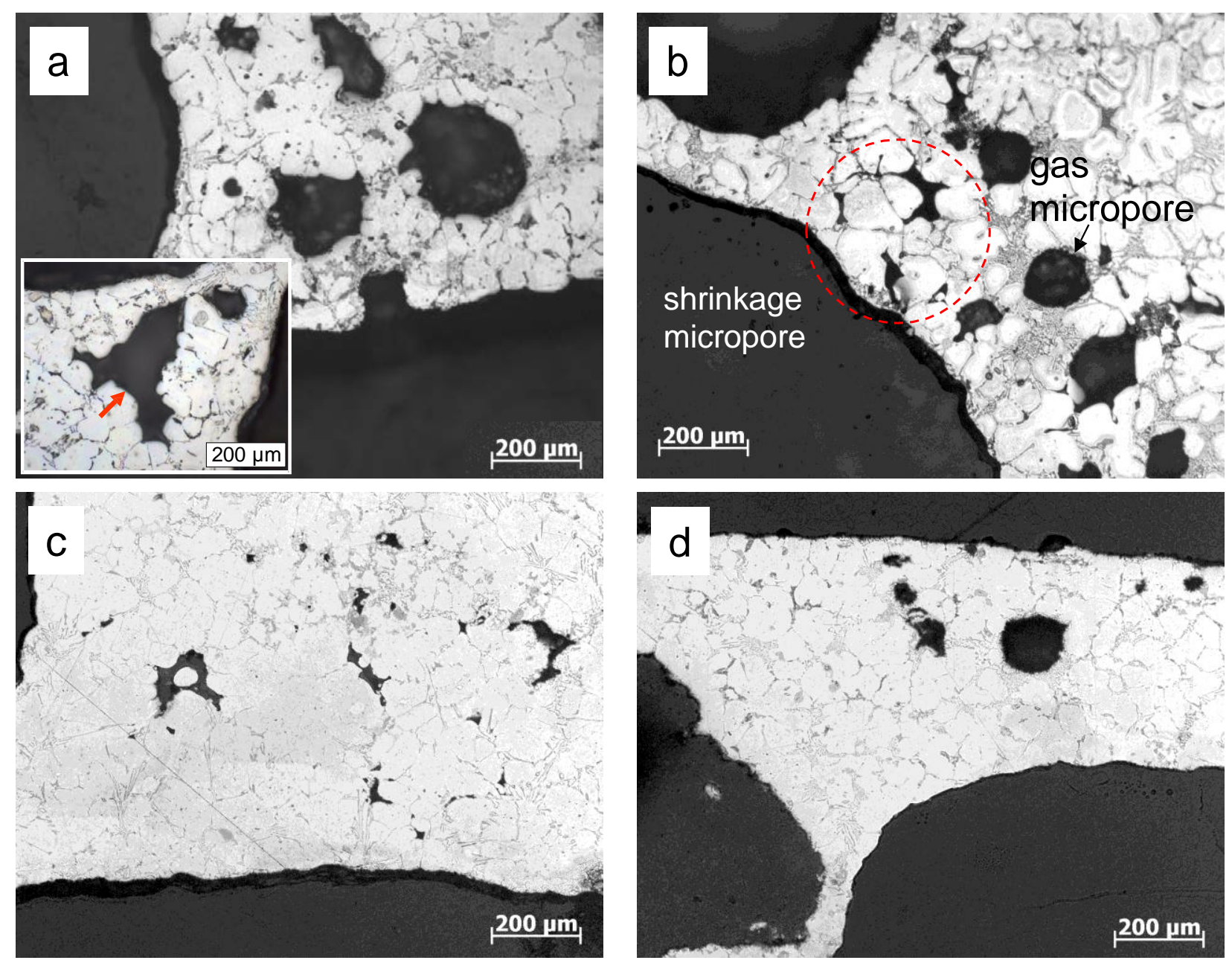

Figure 2: Microstructures of AlSi6Cu4 foams. The HTs are (a) 200 s, (b) 600 s, (c) 1000 s, (d) 2500 s. Inset of Fig. 2a: An arrow indicates a micropore in the cell wall of a AlSi6Cu4 (200 s HT) foam. 

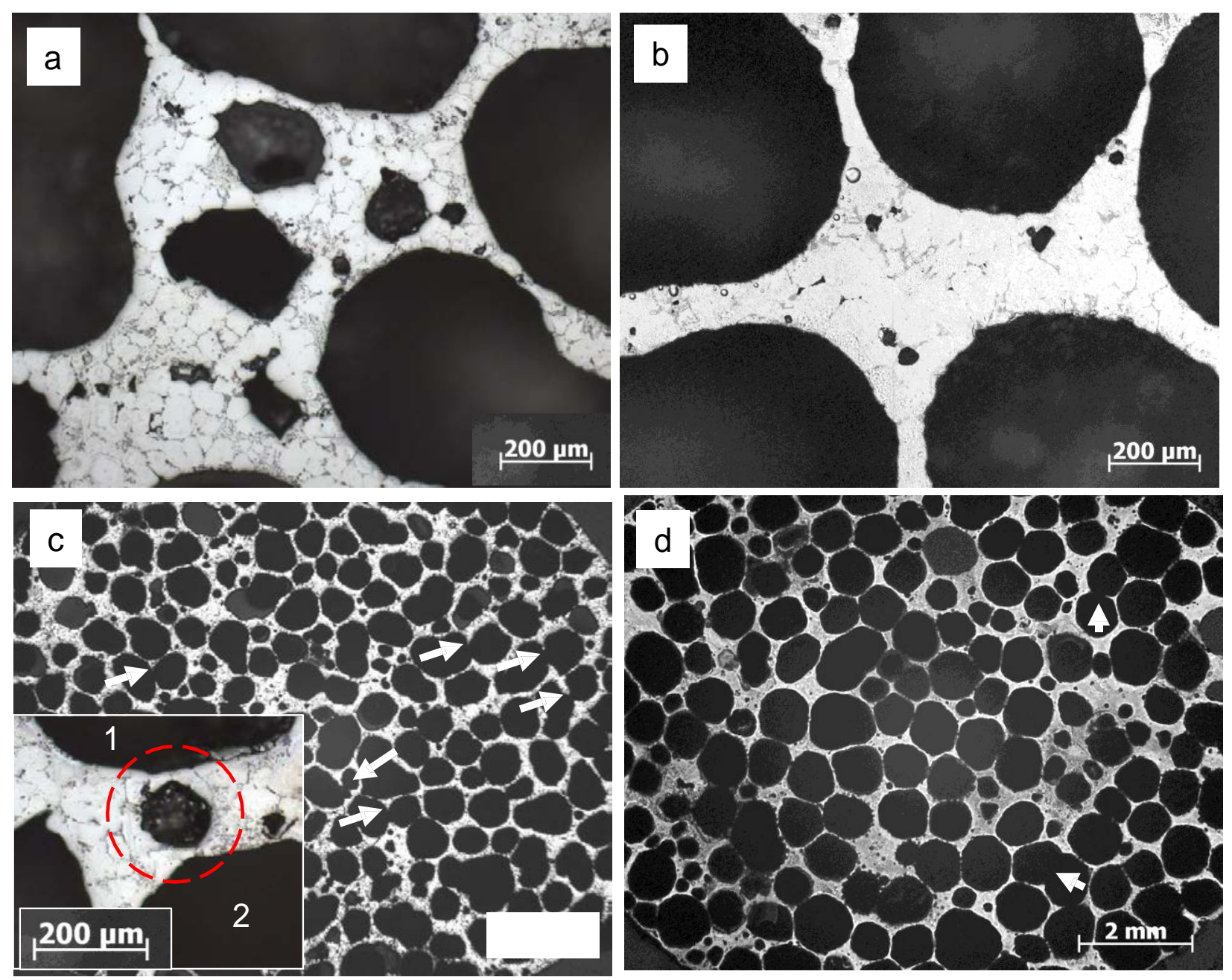

Figure 3: Micro- and macrostructures of AlSi6Cu4 foamed without $\mathrm{TiH}_{2}$. The HTs for (a) and (c) are $200 \mathrm{~s}$, and for (b) and (d) 1500 s. The arrows in (c) and (d) indicate broken cell walls. The inset in Fig. 3c shows a micropore (marked by dashed circle). 


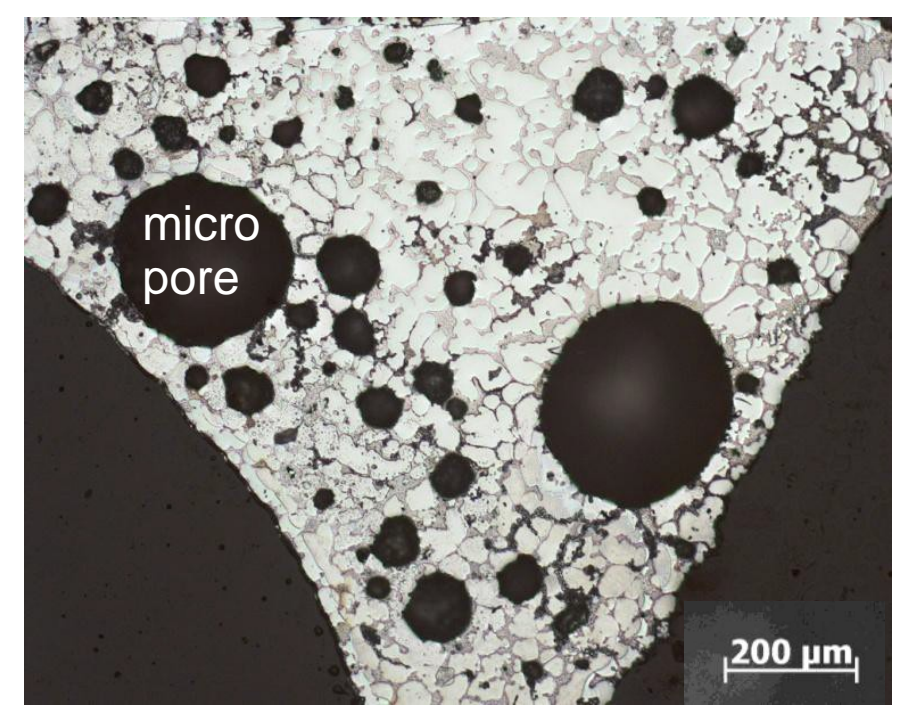

Figure 4: Microstructure of AlCu13Mg4 foam. HT is 200 s.

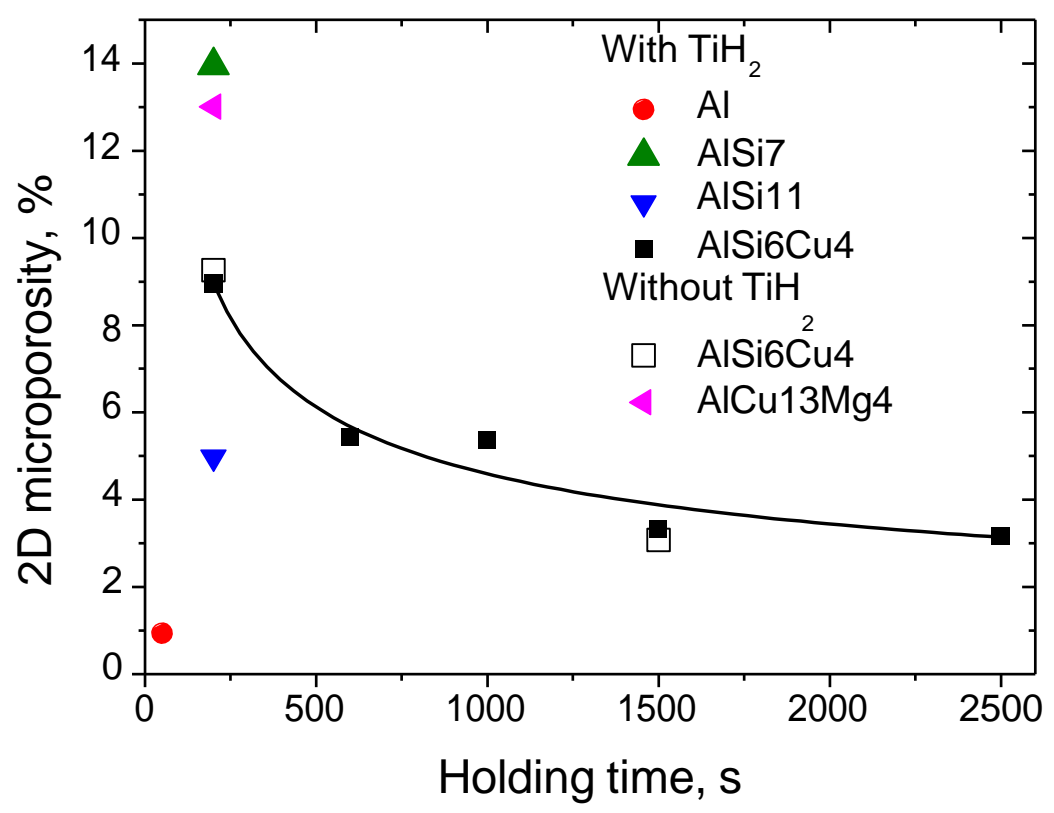

Figure 5: 2D microporosity, as defined in Eq. 2, for different HTs. The solid line is the fit of the data for AlSi6Cu4 (foamed with $\mathrm{TiH}_{2}$ ). 

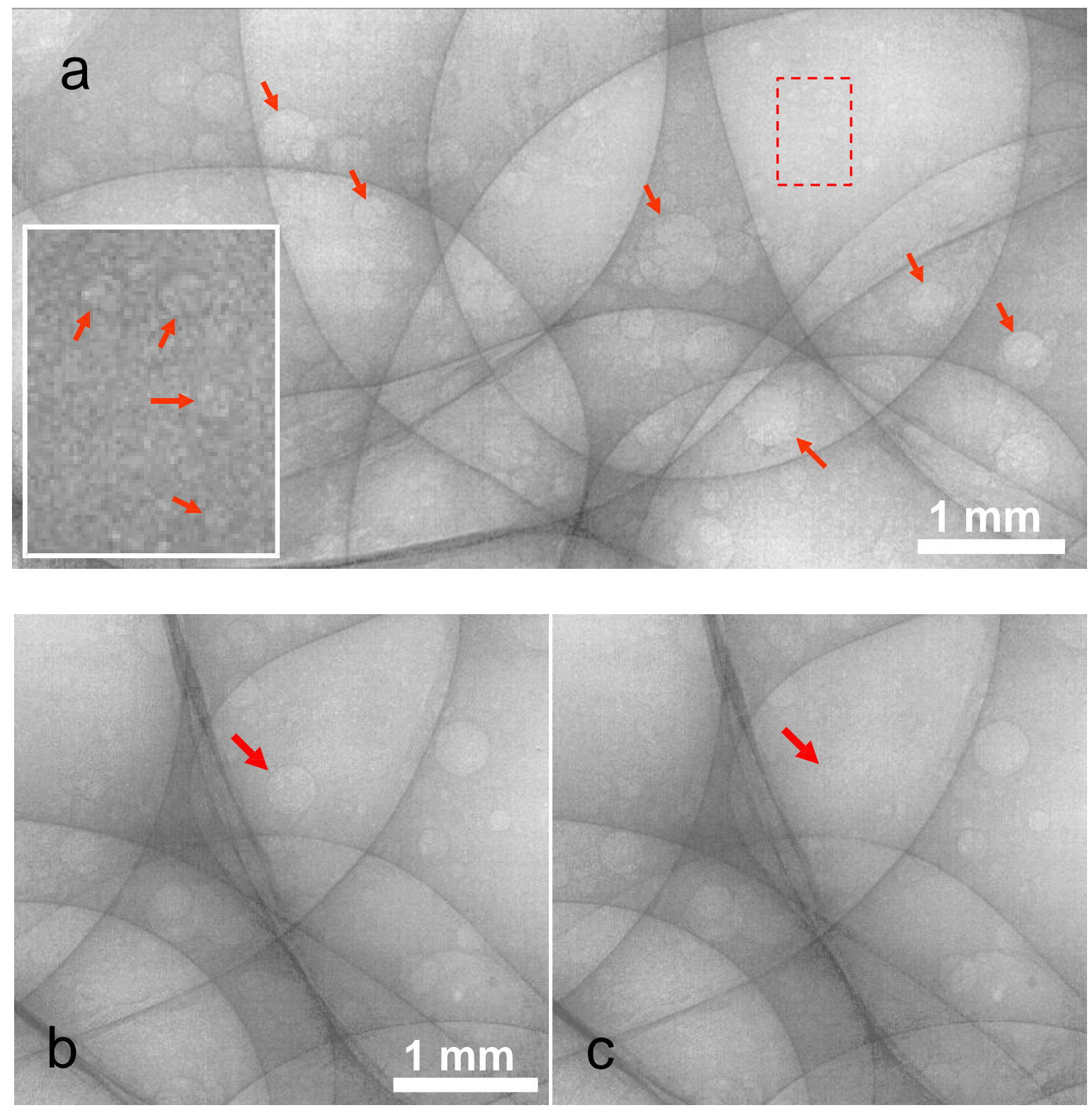

Figure 6: (a-c) Radiographs of AlSi6Cu4 foam in the liquid state as imaged by synchrotron X-ray radioscopy. Microbubbles are seen as small circular objects, some of which are indicated by arrows. Inset of Fig. 6a: Enlarged and contrast-modified view of the region in (a) defined by broken rectangle. The microbubbles marked by arrows in the inset are present in the flat part of a cell wall and range between $50 \mu \mathrm{m}$ and $100 \mu \mathrm{m}$ in diameter. The width of the inset is 500 
$\mu \mathrm{m}$. The microbubble indicated by an arrow in (b) disappears $800 \mu$ s later in (c). (Exposure time $800 \mu \mathrm{s}, 1250$ frames/s, spatial resolution $9 \mu \mathrm{m}$ ) 

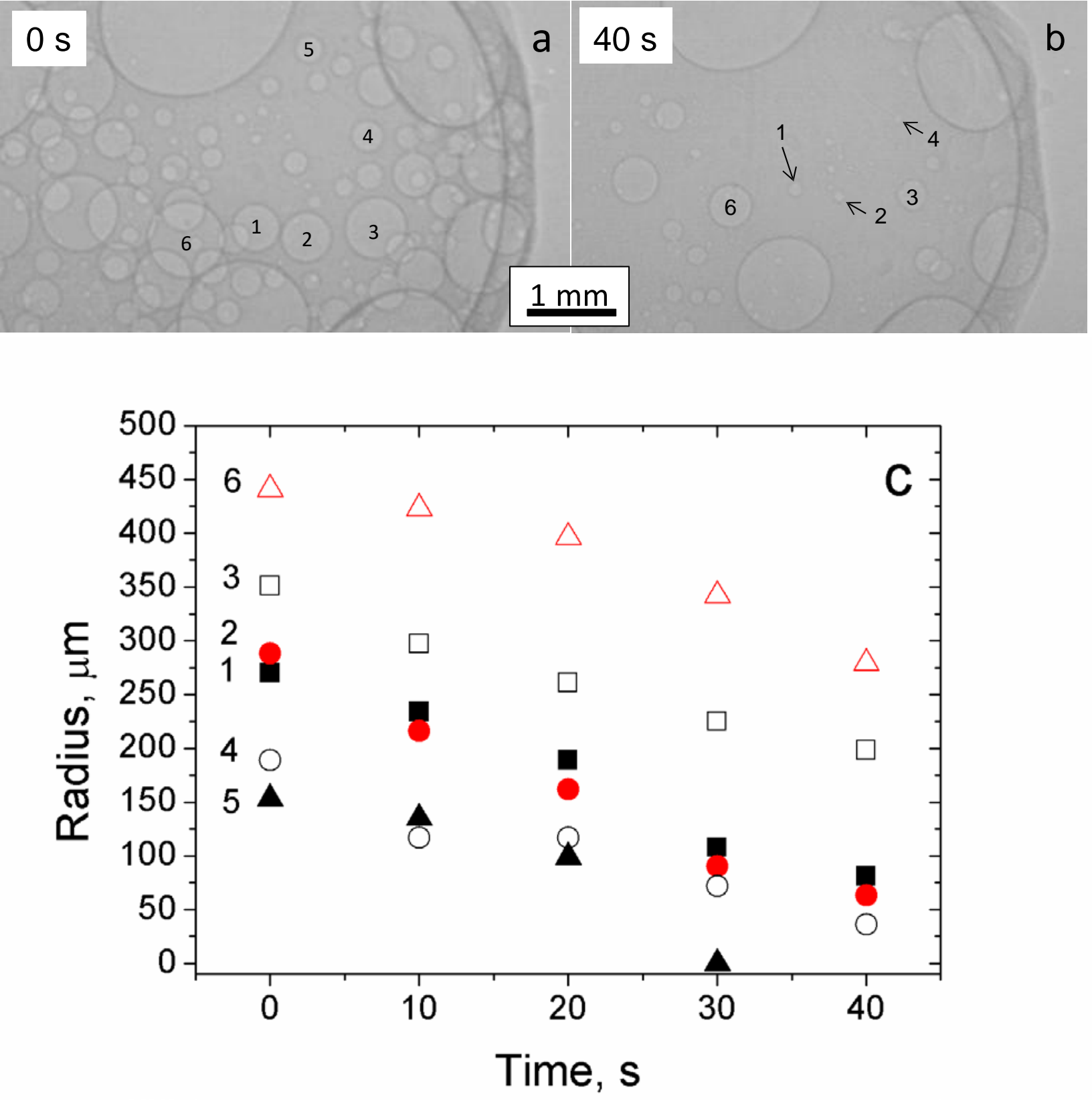

Figure 7: (a-b) Radiographs of $\mathrm{Al}$ foam in the liquid state as imaged by synchrotron X-ray radioscopy. In (a) six microbubbles are marked by numbers 1-6. The evolution of these microbubbles is presented in terms of radius vs. time in (c). The numbers beside each type of symbol in (c) indicate a microbubble in (a) with the same number. The radiographs in (a) and (b) correspond to the $0 \mathrm{~s}$ and $40 \mathrm{~s}$ stage of (c), respectively. (For (a) and (b): exposure time $66 \mu \mathrm{s}$, spatial resolution $18 \mu \mathrm{m}$, images were captured at an interval of $10 \mathrm{~s}$ ) 

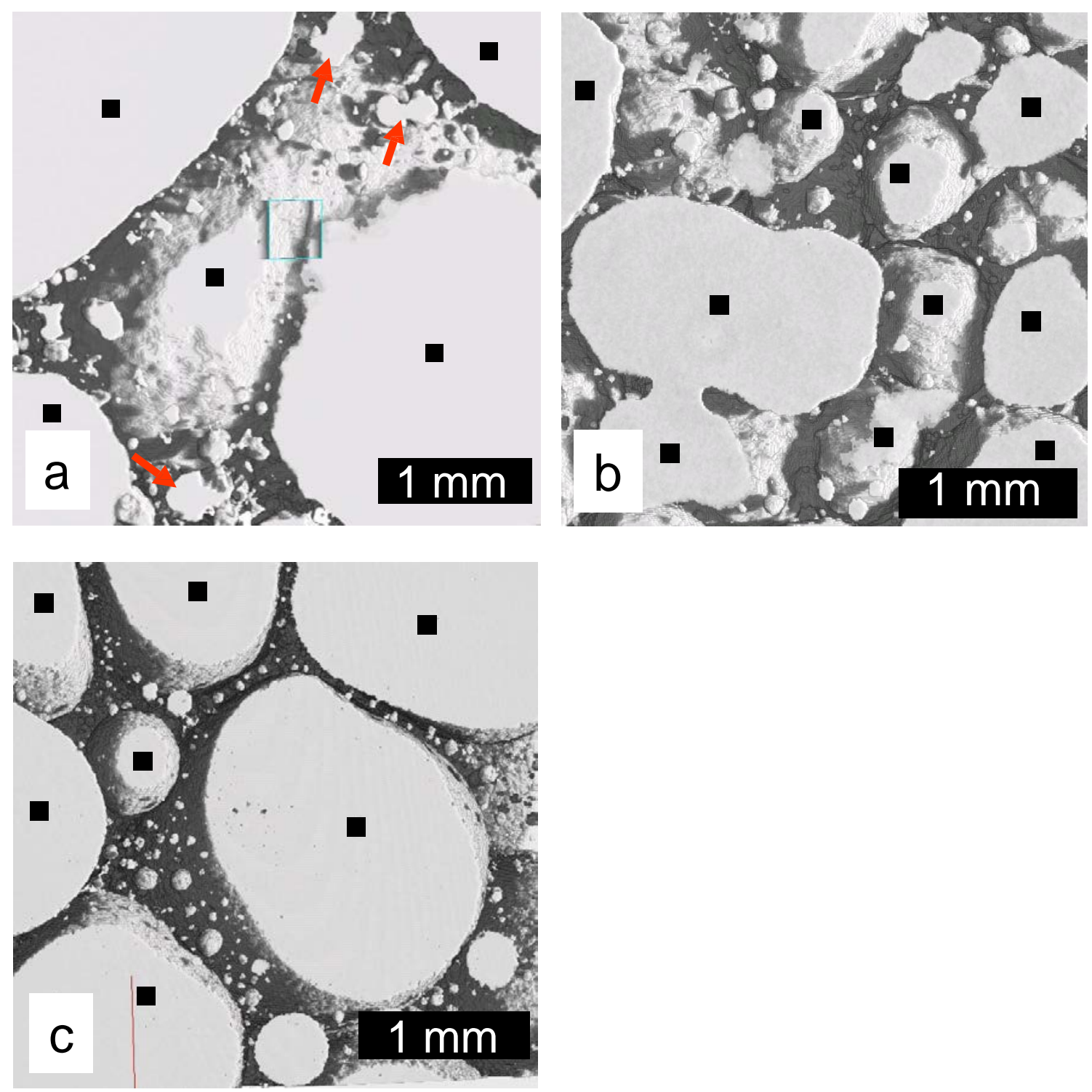

Figure 8: 3D X-ray tomographic reconstruction of solid foam where only cells and micropores are shown as white objects and the metal is made transparent. These images were obtained by rendering 3D datasets and illuminating the 3D volume with a light source from the right. This light source producesshadows which appears dark and improve visibility of features. (a) AlSi6Cu4 foam, (b) AlSi6Cu4 foamed without $\mathrm{TiH}_{2}$ and (c) AlCu13Mg4 foam. All samples were foamed with $200 \mathrm{~s}$ HT. Cells are marked by solid squares. The micropores are seen as small objects between cells. Arrows in (a) indicate elongated pores. 


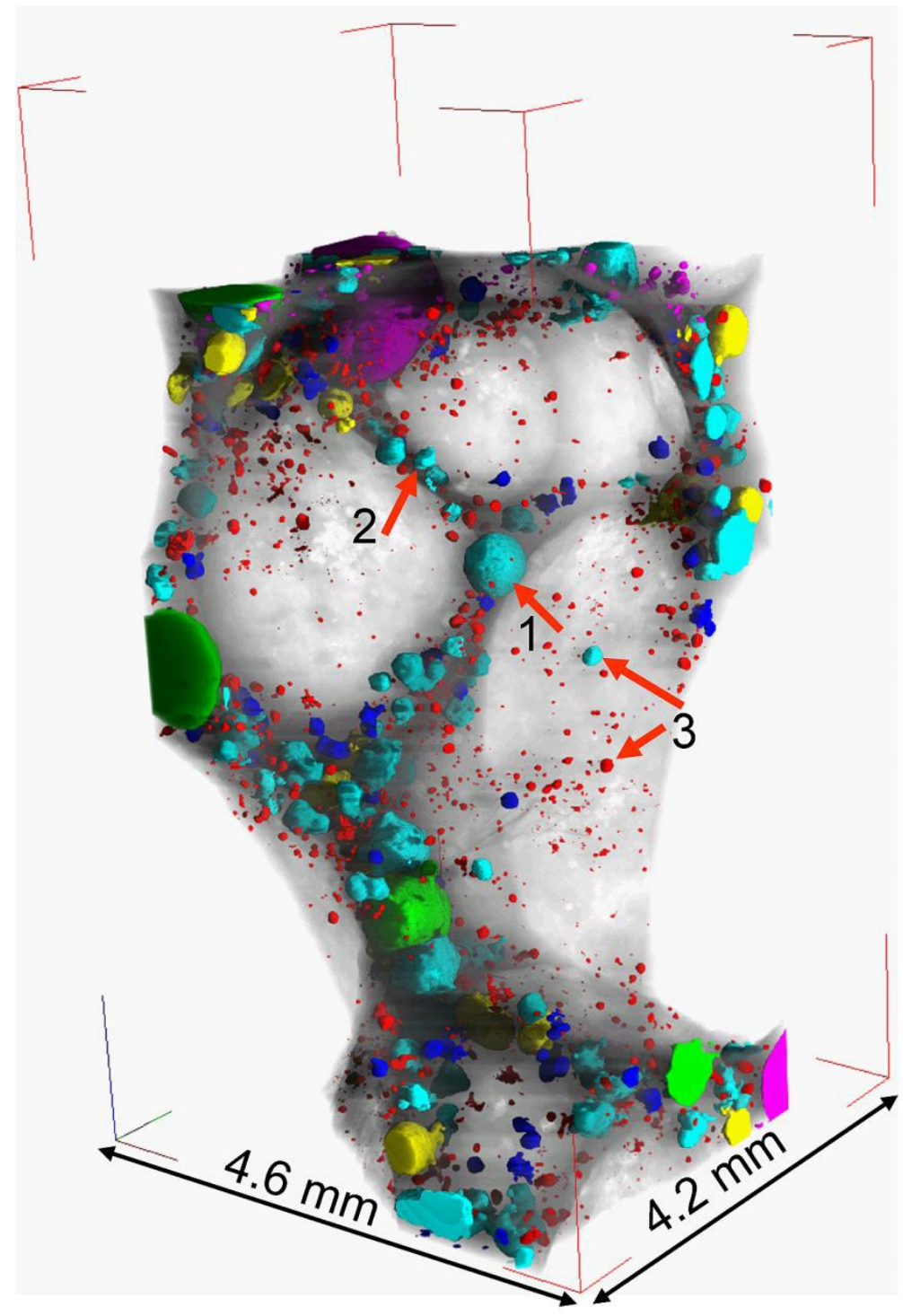

Figure 9: 3D visualization obtained by X-ray tomography of the arrangement of micropores (coloured objects) in solid AlSi6Cu4foam (200 s HT). Cells are omitted from this volume, and metallic matrix is made partially transparent. Micropore(s) inside nodes, a Plateau border and a cell wall are indicated by arrows numbered 1, 2 and 3, respectively. The colours of the micropores merely help to distinguish different micropores. 

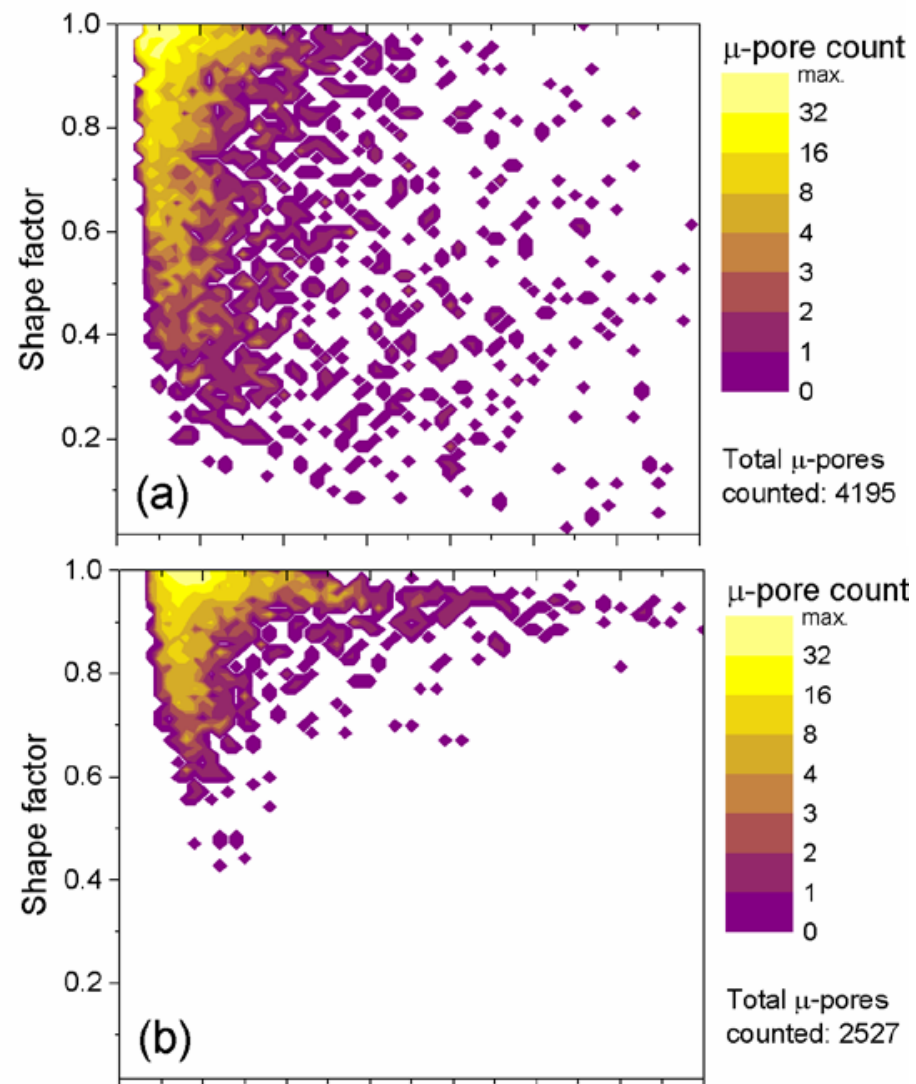

Total $\mu$-pores counted: 2527

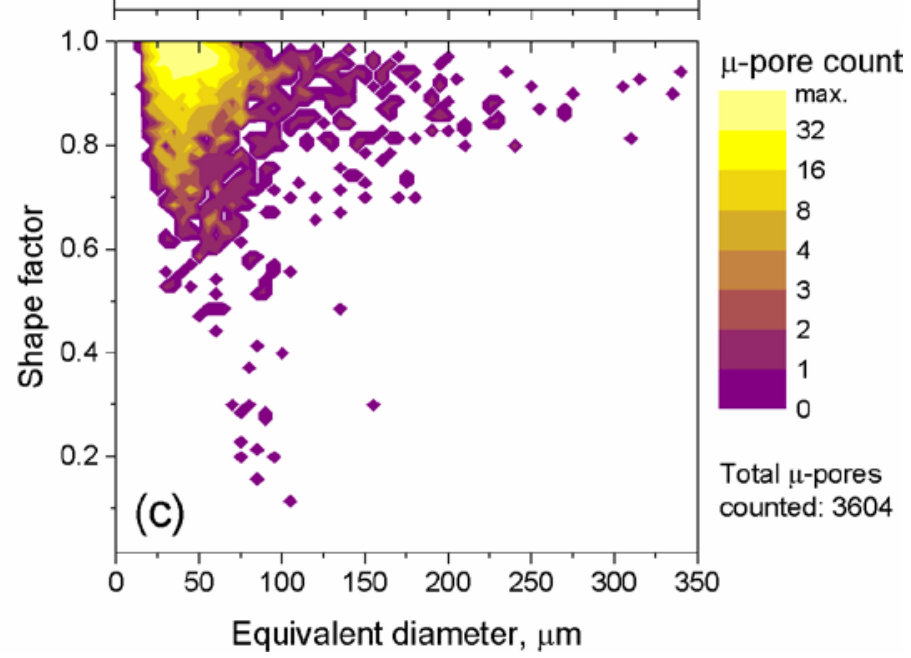

Figure 10: Micropore count (colour-scale) for the foams shown in Fig. 8 vs. shape factor and equivalent diameter for (a) AlSi6Cu4, (b) AlSi6Cu4 without $\mathrm{TiH}_{2}$ and (c) AlCu13Mg4 alloys, all foamed with 200s HT. Both analysed ranges $0-350 \mu \mathrm{m}$ for equivalent diameter and $0-1$ for shape factor were divided into 70 intervals. Total micropores counted are also indicated. 


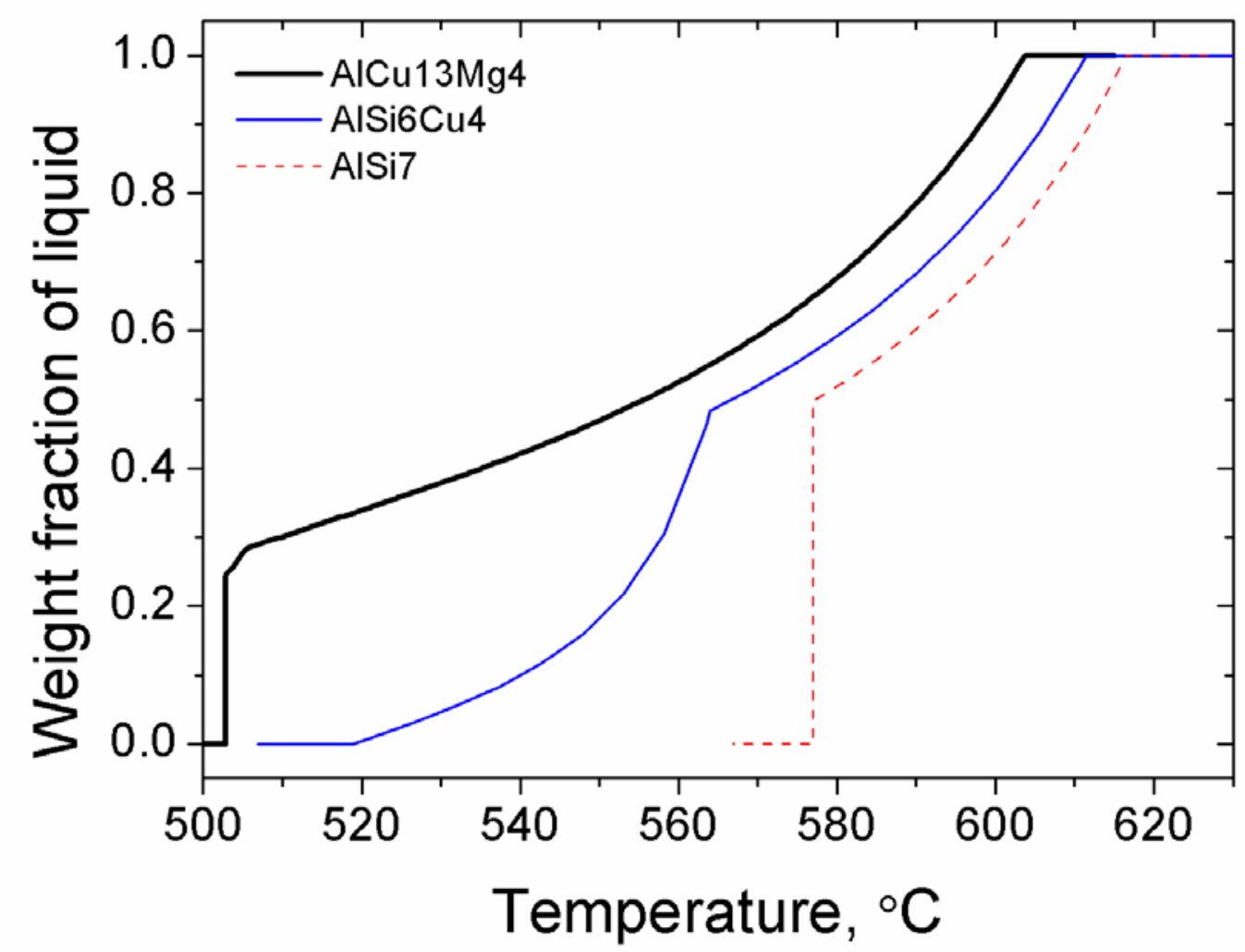

Figure 11: Liquid fraction as a function of temperature during solidification of AlSi7, AlSi6Cu4 and AlCu13Mg4 alloys as calculated using Thermo-Calc software. 


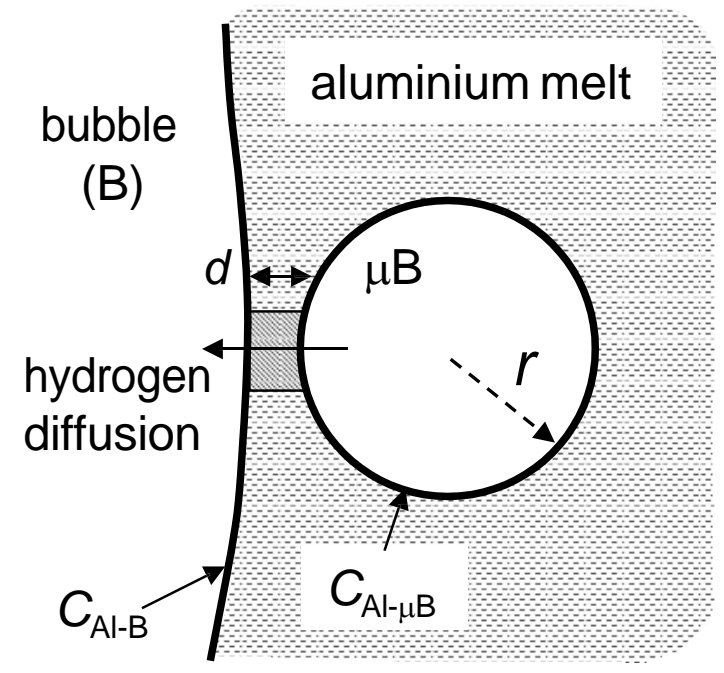

Figure 12: Schematic of hydrogen diffusion from a microbubble $(\mu \mathrm{B})$ to a bubble $(\mathrm{B})$ in aluminium foam. $r$ is the radius of the microbubble, $d$ is the minimum distance between the microbubble and the bubble. It is assumed that diffusion takes place only through the shaded region which in $3 \mathrm{D}$ covers $10 \%$ of the microbubble surface. $C_{\mathrm{Al}-\mu \mathrm{B}}$ and $C_{\mathrm{Al}-\mathrm{B}}$ represent the concentration of hydrogen at the gas-melt interface of the microbubble and bubble, respectively. 


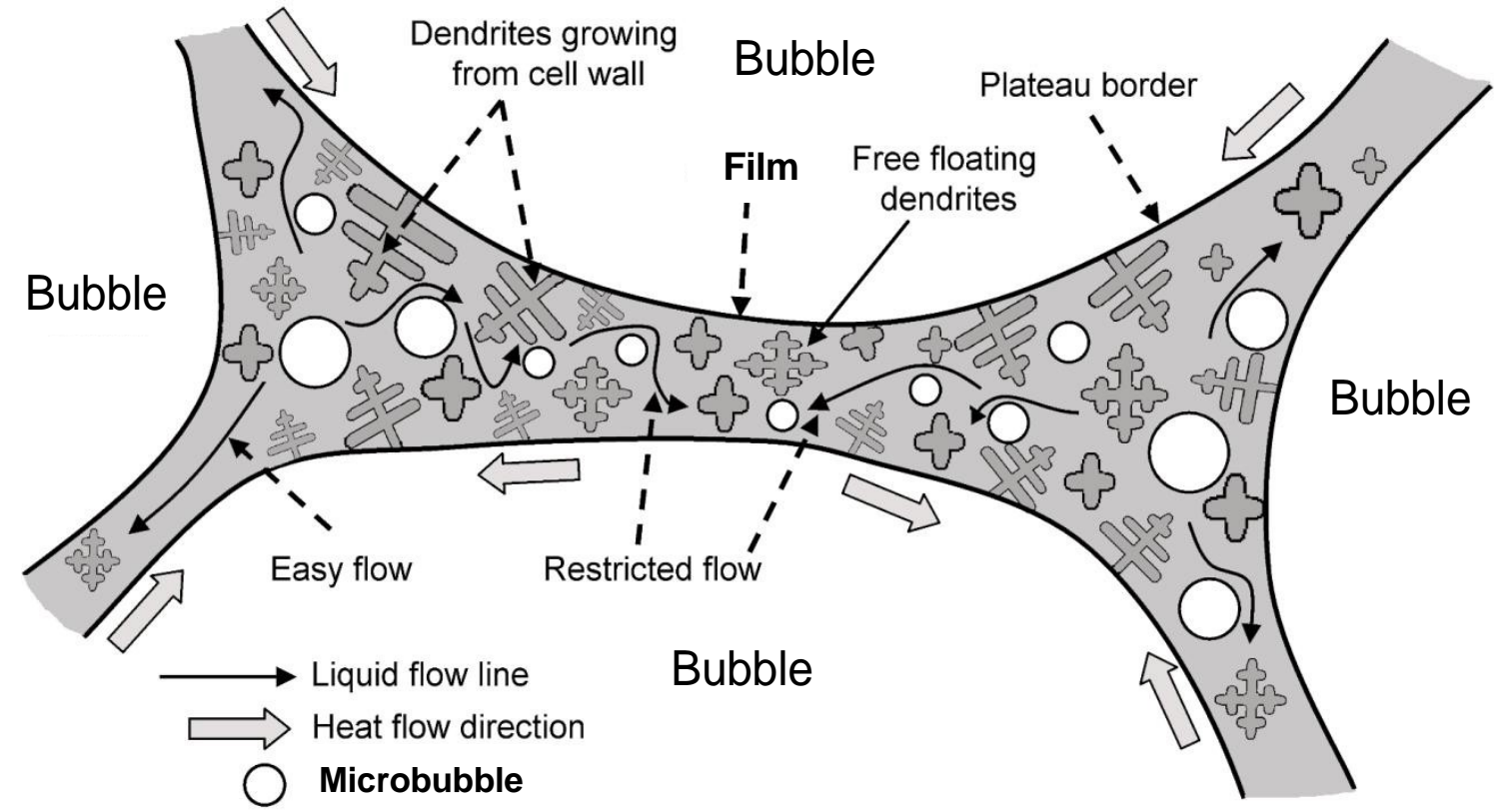

Figure 13: Sketch of the solidification shrinkage-induced liquid flow inside films and Plateau borders in the semi-solid state in the presence of micropores (microbubbles). 

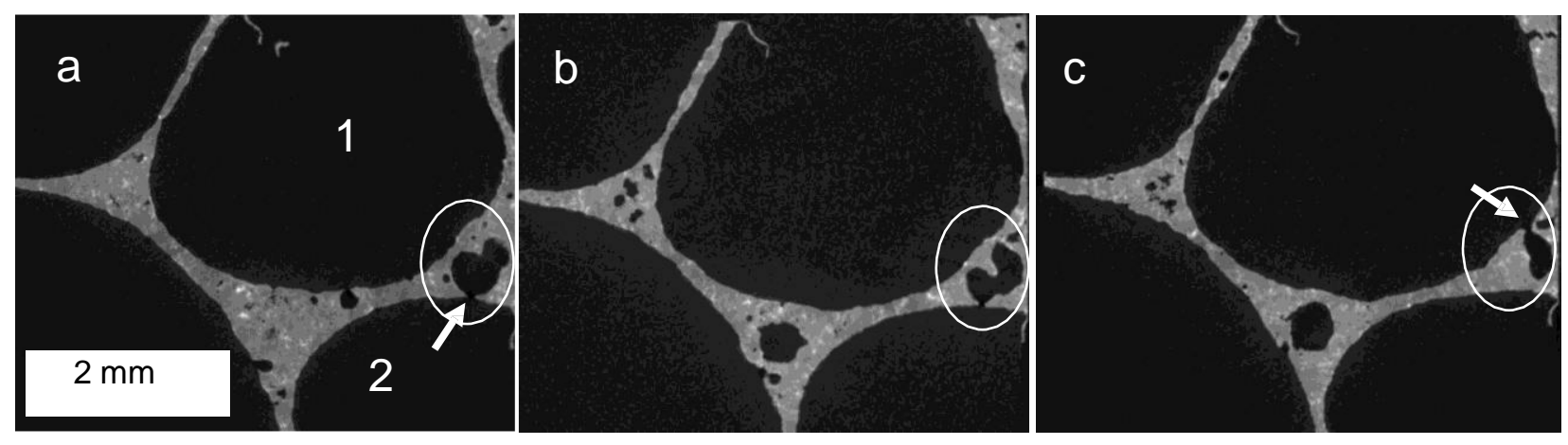

Figure 14: 2D X-ray tomographic sections of a cell wall in solid AlSi6Cu4 (200 s HT) foam at three different depths with respect to the direction perpendicular to the image plane.

Interconnection of two cells (1 and 2) through a micropore (marked by ellipse) is shown. The connecting points are indicated by arrows. The distance between the sections in (a) and (b) is $\sim 107 \mu \mathrm{m}$, in (b) and (c) $\sim 72 \mu \mathrm{m}$. 
Click here to download Supplementary Material: Mukherjee-Supplementary-materials.docx Supplementary Materials
Click here to download Su

\begin{abstract}
.
\end{abstract}

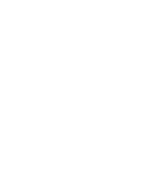

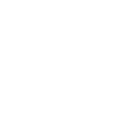

(1)

(1)

(1)

(1)

(1)

(1)

.

.

.

.

.

.

.

.

.

.

.

.

.

.

.

.

.

.

.

.

.

.

.

.

.

.

.

. 
3D visualization obtained by X-ray tomography of the arrangement of micropores (coloured objects) in solid AISi6Cu4 foam

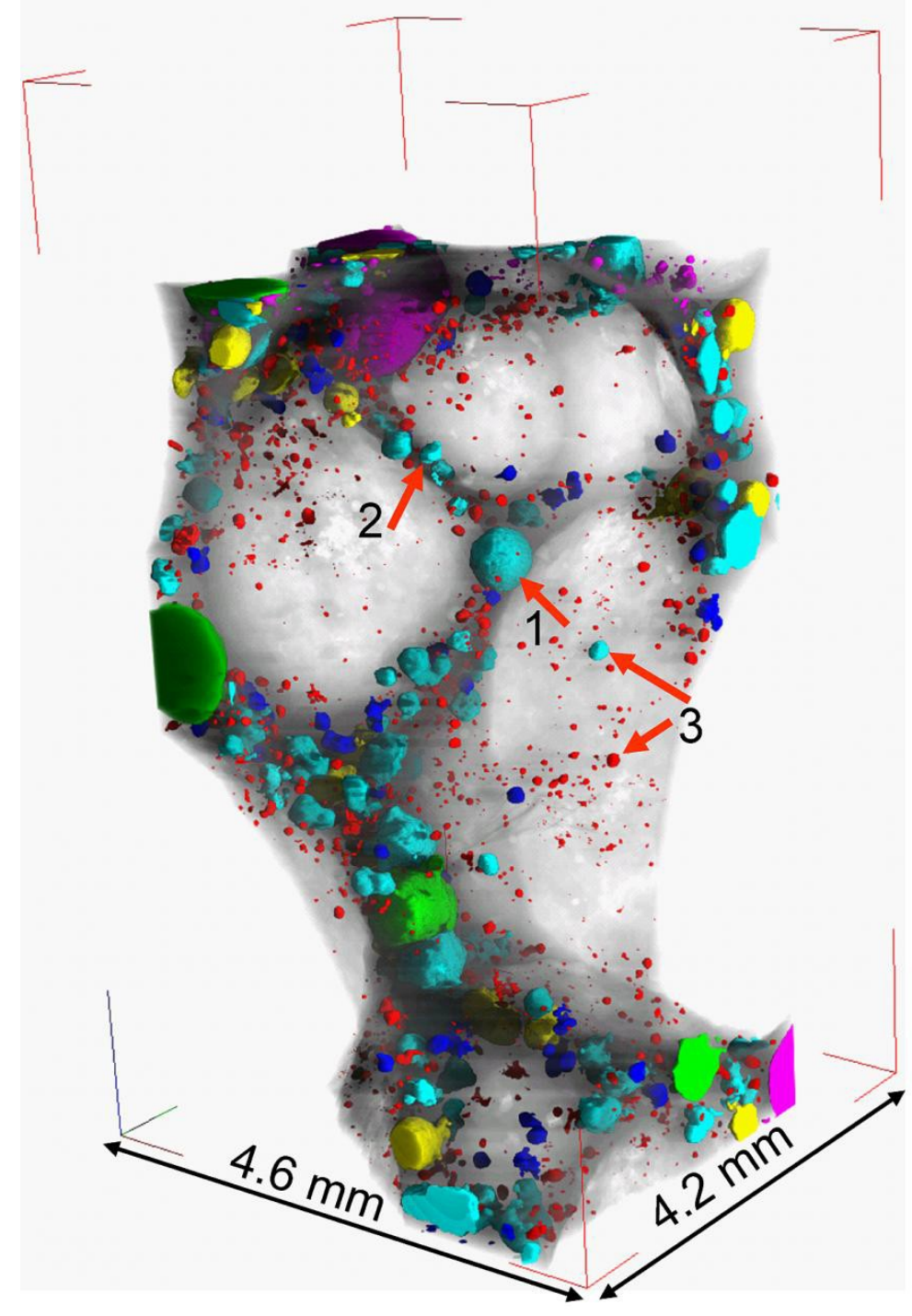

